\title{
ESTUDIO MÉTRICO-LINGÜÍSTICO DE LAS COPLAS A LA MUERTE DE SU PADRE DE JORGE MANRIQUE
}

\author{
M. ' José QuiLIS
}

Resumen: En nuestro artículo realizamos un comentario métrico y prosódico de las Coplas de Jorge Manrique. Estudiamos el análisis silábico, acentual, de las pausas, del tono y de la rima; en cada uno de ellos, se aportan todos los versos que configuran dichos niveles. Este trabajo pormenorizado sirve también de complemento al artículo de don Tomás Navarro Tomás: "Métrica de Las Coplas de Jorge Manrique", por todos los datos aportados que no aparecen en él. Para ello, hemos utilizado la edición de Antonio Serrano de Haro: Obras completas. Madrid, Ed. Alhambra, 1986.

Palabras clave: Comentario métrico y entonativo de las coplas manriqueñas.

Abstract: In this article we will be carrying out a metric and prosodic commentary of Jorge Manrique's Coplas. We will study the analysis of syllables, stresses, tones and rhythms; in each of these, we will include the verses conforming such levels. This indepth study will act as a complement to Navarro Tomas' article: "Métrica de Las Coplas de Jorge Manrique", due to all the new data provided that does not show up in his work. We have thus used Atonio Serrano de Haro's edition: Obras completas. Madrid, Ed. Alhambra, 1986.

Key words: Metric and Intonation commentary of the Coplas Manriqueñas. 



\section{Copla 1}

1. Re - cuér- de el - ál - ma - dor - mí - da $\downarrow / /$ No DE Síl. RIMA

$\left(2^{\mathrm{a}}, 4^{\mathrm{a}}, 7^{\mathrm{a}}\right.$ mixto $)$

a- ví - ve el - sé - so y - des - piér - te $\uparrow / /$

$\left(2^{\mathrm{a}}, 4^{\mathrm{a}}, 7^{\mathrm{a}}\right.$ mixto $)$

con - tem - plán - do $\uparrow / /$

$\left(3^{\mathrm{a}}\right)$

có - mo - se - pá - ssa- la - ví - da $\downarrow / /$

$\left(1^{\mathrm{a}}, 4^{\mathrm{a}}, 7^{\mathrm{a}}\right.$ dactílico)

5. có - mo - se - vié - ne- la - muér - te $\uparrow / /$

$\left(1^{\mathrm{a}}, 4^{\mathrm{a}}, 7^{\mathrm{a}}\right.$ dactílico)

tan - ca - llán - do

$\left(3^{\mathrm{a}}\right)$

8

a

8

$\mathrm{b}$

4

8

a

$8 \quad \mathrm{~b}$

4

cuán - prés - to - se - vá el - pla - zér $\downarrow / /$ \& 8

$\left(1^{\mathrm{a}}, 2^{\mathrm{a}}, 5^{\mathrm{a}}, 7^{\mathrm{a}}\right.$ mixto $)$

có - mo - $\uparrow /$ des - pués - de a - cor - dá - do $\uparrow / / 8$

$\left(1^{\mathrm{a}}, 4^{\mathrm{a}}, 7^{\mathrm{a}}\right.$ dactílico)

dá - do - lór $\downarrow / /$

$\left(1^{\mathrm{a}}, 3^{\mathrm{a}}\right.$ trocaico $)$

c

$8 \quad \mathrm{~d}$

$8 \quad \mathrm{e}$

10. có - mo $\uparrow / \mathrm{a}$ - nués - tro - pa - res - cér $\uparrow / / 8$

$\left(1^{\mathrm{a}}, 3^{\mathrm{a}}, 7^{\mathrm{a}}\right.$ trocaico $)$

cual - quié - ra - tiém - po - pa - ssá - do $\uparrow / / 8$

$\left(2^{\mathrm{a}}, 4^{\mathrm{a}}, 7^{\mathrm{a}}\right.$ mixto)

fué - me - jór $\downarrow / / /$

$\left(1^{\mathrm{a}}, 3^{\mathrm{a}}\right.$ trocaico $)$

4

$\mathrm{f}$

d

$8+$ e

4

Copla 2

$\mathrm{Y}$ - pues - vé - mos - lo - pre - sén - te $\uparrow / / \quad 8 \quad 8 \quad \mathrm{~g}$

$\left(2^{\mathrm{a}}, 3^{\mathrm{a}}, 7^{\mathrm{a}}\right.$ trocaico)

Có - mo en - ún - pún - to - s'és - í - do $\uparrow / / \quad 8 \quad \mathrm{~h}$

$\left(1^{\mathrm{a}}, 3^{\mathrm{a}}, 4^{\mathrm{a}}, 5^{\mathrm{a}}, 7^{\mathrm{a}}\right.$ trocaico)

15. $\mathrm{y} \mathrm{a}-\mathrm{ca}-\mathrm{b}$ á $-\mathbf{d o} \downarrow / /$

\begin{tabular}{|c|c|}
\hline $\begin{array}{c}\mathrm{si}-\mathrm{juz}-\mathrm{gá}-\underset{\left(3^{\mathrm{a}}, 5^{\mathrm{a}}, 7^{\mathrm{a}} \text { trocaico }\right)}{\operatorname{mos}}-\mathrm{mé}-\text { te } \uparrow / / \\
\end{array}$ & 8 \\
\hline $\begin{array}{c}\mathrm{da}-\text { ré }-\operatorname{mos}-\text { lo }- \text { nó }- \text { ve }- \text { ní }- \text { do } \uparrow / / \\
\left(2^{\mathrm{a}}, 5^{\mathrm{a}}, 7^{\mathrm{a}} \text { mixto }\right)\end{array}$ & 8 \\
\hline por - pa - ssá $-\underset{\left(3^{\text {a }}\right)}{\text { do }} \downarrow / / /$ & 4 \\
\hline $\begin{array}{c}\text { Nó }- \text { se en }- \text { gá }-\tilde{\text { ne }}-\text { ná }-\operatorname{die} \uparrow / \text { - nó } \downarrow / / \\
\left(1^{\mathrm{a}}, 3^{\mathrm{a}}, 5^{\mathrm{a}}, 7^{\mathrm{a}} \text { trocaico }\right)\end{array}$ & 8 \\
\hline $\begin{array}{l}\text { 20. pen - sán - do - que há }- \text { de }- \text { du }- \text { rár } \uparrow / / \\
\left(2^{\mathrm{a}}, 4^{\mathrm{a}}, 7^{\mathrm{a}} \text { mixto }\right)\end{array}$ & 8 \\
\hline
\end{tabular}




$$
\begin{aligned}
& \text { lo-que es - pé - ra } \uparrow / / \quad 4 \quad \mathrm{k} \\
& \text { más - que - du - ró - lo - que - vió } \downarrow / / \quad 8 \\
& \left(1^{\mathrm{a}}, 4^{\mathrm{a}}, 7^{\mathrm{a}}\right. \text { dactílico) } \\
& \text { por - que - tó - do há - de - pa - ssár } \uparrow / / \quad 8 \\
& \left(3^{\mathrm{a}}, 4^{\mathrm{a}}, 7^{\mathrm{a}}\right. \text { trocaico) } \\
& \text { por - tál - ma - né - ra } \downarrow / / / \\
& \left(2^{\mathrm{a}}, 4^{\mathrm{a}} \text { yámbico }\right)
\end{aligned}
$$

\section{Copla 3}

25. Nues - tras - ví - das - són - los - rí - os $\rightarrow 8$ $\left(3^{\mathrm{a}}, 5^{\mathrm{a}}, 7^{\mathrm{a}}\right.$ trocaico)

que - ván - a - dár - en - la - már $\downarrow / /$ $\left(2^{\mathrm{a}}, 4^{\mathrm{a}}, 7^{\mathrm{a}}\right.$ mixto $)$

que és - el - mo - rír $\downarrow / /$
$\left(1^{\mathrm{a}}, 4^{\mathrm{a}}\right.$ dactílico $)$

a- llí - ván - los - se - ño - rí - os $\rightarrow$

$\left(2^{\mathrm{a}}, 3^{\mathrm{a}}, 7^{\mathrm{a}}\right.$ trocaico $)$

de - ré - chos - a - se a- ca - bár $\uparrow / /$ $\left(2^{\mathrm{a}}, 7^{\mathrm{a}}\right.$ mixto)

30. y-con-su-mír $\downarrow / / /$

$$
\begin{aligned}
& \mathrm{a}-\text { llí }- \text { los }- \text { rí }- \text { os }- \text { cau }- \text { dá }- \text { les } \downarrow / / \\
& \left(2^{\mathrm{a}}, 4^{\mathrm{a}}, 7^{\mathrm{a}} \text { mixto }\right) \\
& \text { a - llí - los - ó - tros } \uparrow / \text { - me - diá - nos } \uparrow / / \\
& \left(2^{\mathrm{a}}, 4^{\mathrm{a}}, 7^{\mathrm{a}} \text { mixto }\right)
\end{aligned}
$$$$
\text { y - más - chí - cos } \downarrow / /
$$$$
\left(2^{\mathrm{a}}, 3^{\mathrm{a}} \text { trocaico }\right)
$$

$\mathrm{m}$

\section{$\mathrm{a}$ - lle - gá - dos - són - i - guá - les $\uparrow / /$ \\ $\left(3^{\mathrm{a}}, 5^{\mathrm{a}}, 7^{\mathrm{a}}\right.$ trocaico)}

35. los - que - ví - ven - por - sus - má - nos $\uparrow / /$ $\left(3^{\mathrm{a}}, 7^{\mathrm{a}}\right.$ trocaico)

$$
\mathrm{y}-\operatorname{los}-\mathrm{rí}-\cos \downarrow / / /
$$

\section{Copla 4}

$$
\begin{aligned}
& \text { Dé - xo - las - in - vo - ca - ció - nes } \rightarrow \\
& \left(1^{\mathrm{a}}, 7^{\mathrm{a}} \text { dactílico }\right) \\
& \text { de - los - fa - mó - sos - po - é - tas } \uparrow / / \\
& \left(4^{\mathrm{a}}, 7^{\mathrm{a}}\right. \text { dactílico) } \\
& \text { y o-ra-dó - res } \downarrow / / \\
& \left(3^{\mathrm{a}}\right)
\end{aligned}
$$

40. nó - cú - ro - de - sus - fic- ció - nes $\uparrow / /$

$\left(1^{\mathrm{a}}, 2^{\mathrm{a}}, 7^{\mathrm{a}}\right.$ mixto $)$ 


$$
\begin{aligned}
& \text { que - trá - en - yér - bas - se - cré - tas } \uparrow / / \\
& \left(2^{\mathrm{a}}, 4^{\mathrm{a}}, 7^{\mathrm{a}}\right. \text { mixto) } \\
& \text { sus }- \text { sa }- \text { bó }- \text { res } \downarrow / / / \\
& \left(3^{\mathrm{a}}\right) \\
& \text { A a - quél - só - lo - me en - co - mién - do } \downarrow / / \quad 8 \quad \mathrm{~s} \\
& \left(2^{\mathrm{a}}, 3^{\mathrm{a}}, 7^{\mathrm{a}} \text { trocaico }\right) \\
& \text { A - quél - só - lo in - vó - co - yó } \downarrow / / \text { ( } 8 \\
& \left(2^{\mathrm{a}}, 3^{\mathrm{a}}, 5^{\mathrm{a}}, 7^{\mathrm{a}} \text { trocaico }\right) \\
& \text { 45. de - ver - dád } \underset{\left(3^{\mathrm{a}}\right)}{\downarrow}
\end{aligned}
$$

\section{Copla 5}

És - te - mún - do és - el - ca - mí- no $\uparrow / / \quad 8$

50. pa - ra el - ó - tro $\uparrow /$ que és - mo - rá - da $\rightarrow$ $\left(3^{\mathrm{a}}, 5^{\mathrm{a}}, 7^{\mathrm{a}}\right.$ trocaico) $\sin$ - pe - sár $\left.\downarrow / / 3^{\mathrm{a}}\right)$

mas - cúm - ple - te - nér - buén - tí - no $\uparrow / / \quad 8$

55. Par - tí - mos - cuan - do - nas - cé - mos $\downarrow / /$ $\left(2^{\mathrm{a}}, 7^{\mathrm{a}}\right.$ mixto $)$

$$
\begin{aligned}
& \text { an - dá - mos - mien - tra - vi - ví - mos } \downarrow / / \\
& \left(2^{\mathrm{a}}, 7^{\mathrm{a}} \text { mixto }\right) \\
& \mathrm{y}-\mathrm{lle}-\mathrm{gá}-\operatorname{mos} \uparrow / / \\
& \left(3^{\mathrm{a}}\right) \\
& \text { al - tiém - po - que - fe - nes - cé - mos } \downarrow / / \\
& \left(2^{\mathrm{a}}, 7^{\mathrm{a}} \text { mixto }\right) \\
& \mathrm{a}-\mathrm{ssí}-\text { que } \uparrow / \text { cuan }- \text { do }- \text { mo }- \text { rí }-\operatorname{mos} \uparrow / / \\
& \left(2^{\mathrm{a}}, 7^{\mathrm{a}}\right. \text { mixto) }
\end{aligned}
$$

60. des - can - sá - mos $\downarrow / / /$ 


\section{Copla 6}

\begin{tabular}{|c|c|}
\hline $\begin{array}{c}\text { És }- \text { te }- \text { mún }- \text { do }- \text { bué }- \text { no }- \text { fué } \uparrow / / \\
\left(1^{\mathrm{a}}, 3^{\mathrm{a}}, 5^{\mathrm{a}}, 7^{\mathrm{a}} \text { trocaico }\right)\end{array}$ & 8 \\
\hline $\begin{array}{c}\mathrm{si}-\text { bién }-\mathrm{u}-\mathrm{sá}-\mathrm{re}-\text { mos }- \text { dél } \uparrow / / \\
\left(2^{\mathrm{a}}, 4^{\mathrm{a}}, 7^{\mathrm{a}} \text { mixto }\right)\end{array}$ & 8 \\
\hline co - mo - de $-\underset{\left(4^{\mathrm{a}}\right)}{\mathrm{bé}}-\mathbf{m o s} \downarrow / /$ & 5 \\
\hline 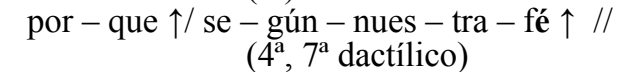 & 8 \\
\hline 55. és - pa - ra $-\underset{\left(1^{\mathrm{a}}, 5^{\mathrm{a}}, 7^{\mathrm{a}} \text { trocaico }\right)}{\text { ga }} \rightarrow$ & 8 \\
\hline que a - ten - dé - mos $\downarrow / / /$ & 4 \\
\hline $\begin{array}{c}\text { Y aun }-\mathrm{el}-\mathrm{hí}-\mathrm{jo}-\mathrm{de}-\text { Diós } \uparrow / / \\
\left(4^{\mathrm{a}}, 7^{\mathrm{a}} \text { dactílico }\right)\end{array}$ & 7 \\
\hline $\begin{array}{c}\mathrm{pa}-\mathrm{ra}-\mathrm{so}-\mathrm{bír}-\text { nos }-\mathrm{al}-\mathrm{cié}-\mathbf{l o} \uparrow / / \\
\left(4^{\mathrm{a}}, 7^{\mathrm{a}} \text { dactílico }\right)\end{array}$ & 8 \\
\hline Des - cen $-\operatorname{dió} \underset{\left(3^{a}\right)}{\longrightarrow}$ & 4 \\
\hline $\begin{array}{c}\text { 70. a - nas - cér - a - cá en - tre - nós } \uparrow / / \\
\left(3^{\mathrm{a}}, 5^{\mathrm{a}}, 7^{\mathrm{a}} \text { trocaico }\right)\end{array}$ & 8 \\
\hline $\begin{array}{c}\mathrm{y}-\mathrm{vi}-\text { vír }- \text { en }- \text { és }- \text { te }- \text { sué }-\mathbf{l o} \rightarrow \\
\left(3^{\mathrm{a}}, 5^{\mathrm{a}}, 7^{\mathrm{a}} \text { trocaico }\right)\end{array}$ & 8 \\
\hline do $-\mathrm{mu}-$ rió $\underset{\left(3^{\mathrm{a}}\right)}{\downarrow / / /}$ & 4 \\
\hline
\end{tabular}

\section{Copla 7}

Véd - de - cuán - pó - co - va - lór $\uparrow / / \quad 8 \quad \mathrm{f}$

$\left(1^{\mathrm{a}}, 3^{\mathrm{a}}, 4^{\mathrm{a}}, 7^{\mathrm{a}}\right.$ trocaico)

Són - las - có - sas - tras - que an - dá - mos $\uparrow / / \quad 8 \quad y$

75. y-co-rré - mos $\downarrow / /$

que $\uparrow /$ en - és - te - mún - do - trai - dór $\uparrow / /$

$\left(2^{\mathrm{a}}, 4^{\mathrm{a}}, 7^{\mathrm{a}}\right.$ mixto $)$

aun - pri-mé - ro - que - mu-rá - mos $\uparrow / / \quad 8 \quad$ y

$\left(3^{\mathrm{a}}, 7^{\mathrm{a}}\right.$ trocaico $)$
las - per - dé $-\operatorname{mos} \downarrow / / /$

dé - llas - des - há - ze - la e- dád $\downarrow / / \quad 8 \quad \mathrm{t}$

$\left(1^{\mathrm{a}}, 4^{\mathrm{a}}, 7^{\mathrm{a}}\right.$ dactílico)

80. dé - llas - cá - sos - de - sás - trá - dos $\rightarrow$

$\left(1^{\mathrm{a}}, 3^{\mathrm{a}}, 7^{\mathrm{a}}\right.$ trocaico)

que a - ca - és - cen $\downarrow / /$

$\left(3^{\mathrm{a}}\right)$

$8-\delta$

$4 \quad \varepsilon$ 


$$
\begin{aligned}
& \text { dé - llas } \uparrow / \text { por }-\mathrm{su}-\mathrm{ca}-\mathrm{li}-\mathrm{dád} \uparrow / / \quad 8 \quad \mathrm{t} \\
& \left(1^{\mathrm{a}}, 7^{\mathrm{a}} \text { dactílico }\right) \\
& \text { en - los - más - ál - tos - es - tá - dos } \uparrow / / \quad 8 \\
& \left(3^{\mathrm{a}}, 4^{\mathrm{a}}, 7^{\mathrm{a}}\right. \text { trocaico) } \\
& \text { des }-\mathrm{fa}-\text { llés - cen } \downarrow / / / \\
& \left(3^{\mathrm{a}}\right)
\end{aligned}
$$

\begin{tabular}{|c|c|}
\hline $\begin{array}{c}\text { 85. De - zíd - me } \downarrow \downarrow \\
\left(2^{\mathrm{a}}, 7^{\mathrm{a}} \text { mixto }\right)\end{array}$ & 8 \\
\hline $\begin{array}{c}\text { la - gen - tíl - fres - cú - ra y - téz } \rightarrow \\
\left(3^{\mathrm{a}}, 5^{\mathrm{a}}, 7^{\mathrm{a}} \text { trocaico }\right)\end{array}$ & 8 \\
\hline $\mathrm{de}-$ la $-\mathrm{cá}-\mathbf{r a} \downarrow / / /$ & 4 \\
\hline $\begin{array}{c}\text { la }- \text { co }- \text { lór }-y-\text { la }- \text { blán }-c \text { cú }-\mathbf{r a} \uparrow / / \\
\left(3^{\mathrm{a}}, 7^{\mathrm{a}} \text { trocaico }\right)\end{array}$ & 8 \\
\hline $\begin{array}{c}\text { cuan }- \text { do }- \text { vié }- \text { ne }- \text { la }- \text { ve }- \text { jéz } \uparrow / / \\
\left(3^{\mathrm{a}}, 7^{\mathrm{a}} \text { trocaico }\right)\end{array}$ & 8 \\
\hline $\begin{array}{r}90 . \text { ¿cuál }-\mathrm{se}-\mathrm{pá}-\mathbf{r a} ? \downarrow / / / / \\
\left(1^{\mathrm{a}}, 3^{\mathrm{a}} \text { trocaico }\right)\end{array}$ & 4 \\
\hline $\begin{array}{c}\text { las - má }-\tilde{\text { nas }}-\mathrm{y}-\mathrm{li}-\mathrm{ge}-\mathrm{ré}-\mathbf{z a} \downarrow / / \\
\left(2^{\mathrm{a}}, 7^{\mathrm{a}} \text { mixto }\right)\end{array}$ & 8 \\
\hline $\begin{array}{c}y-\text { la }- \text { fuér }-c ̧ a-\text { cor }- \text { po }- \text { rál } \\
\qquad\left(3^{\mathrm{a}}, 7^{\mathrm{a}} \text { trocaico }\right)\end{array}$ & 8 \\
\hline de $-\mathrm{ju}-\mathrm{ven}-\underset{\left(4^{\mathrm{a}}\right)}{\uparrow} \uparrow / /$ & 5 \\
\hline $\begin{array}{c}\text { tó }- \text { do }-\mathrm{se}-\text { tór }- \text { na }- \text { gra }- \text { vé }-\mathbf{z a} \uparrow / / \\
\left(1^{\mathrm{a}}, 4^{\mathrm{a}}, 7^{\mathrm{a}} \text { dactílico }\right)\end{array}$ & 8 \\
\hline $\begin{array}{l}\text { 95. cuan }- \text { do }-11 \text { é }- \text { ga al }-\mathrm{a}-\text { rra }- \text { bál } \rightarrow \\
\left(3^{\mathrm{a}}, 7^{\mathrm{a}} \text { trocaico }\right)\end{array}$ & 8 \\
\hline de - se - nec - túd $\left(^{a}\right)$ & 5 \\
\hline
\end{tabular}

\section{Copla 8}

\section{Copla 9}

$$
\begin{aligned}
& \text { Pues - la - sán - gre - de - los - gó - dos } \downarrow / / \quad 8 \quad 8 \quad \tau \\
& \left(3^{\mathrm{a}}, 7^{\mathrm{a}} \text { trocaico }\right) \\
& \text { el - li - ná - je y - la - no - blé - za } \rightarrow \quad 4 \quad 8 \quad \pi \\
& \left(3^{\mathrm{a}}, 7^{\mathrm{a}} \text { trocaico }\right) \\
& \tan -\text { cres - cí - da } \uparrow / / \\
& \text { 100. ¡por - cuán - tas - ví - as - y - mó - dos } \uparrow / / \quad 8 \quad \tau \\
& \left(2^{\mathrm{a}}, 4^{\mathrm{a}}, 7^{\mathrm{a}} \text { mixto }\right) \\
& \text { se - sú - me - su - grán - al - té - za } \uparrow / / \\
& \left(2^{\mathrm{a}}, 5^{\mathrm{a}}, 7^{\mathrm{a}} \text { mixto }\right)
\end{aligned}
$$




\begin{tabular}{|c|c|c|}
\hline $\begin{array}{r}\text { en - és- ta - ví }-\mathbf{d a} ! \downarrow / / / \\
\left(2^{\mathrm{a}}, 4^{\mathrm{a}} \text { yámbico }\right)\end{array}$ & 5 & $\mathrm{a}$ \\
\hline $\begin{array}{c}\text { Ú }- \text { nos }- \text { por }- \text { pó }- \text { co }- \text { va }- \text { lér } \downarrow / / \\
\left(1^{\mathrm{a}}, 4^{\mathrm{a}}, 7^{\mathrm{a}} \text { dactílico }\right)\end{array}$ & 8 & $\mathrm{~d}$ \\
\hline $\begin{array}{c}\text { por }- \text { cuan }- \text { bá }- \text { xos }- \text { y a }- \text { ba }- \text { tí }-\operatorname{dos} \uparrow / / \\
\left(3^{\mathrm{a}}, 7^{\mathrm{a}} \text { trocaico }\right)\end{array}$ & 8 & $\omega$ \\
\hline 105. que $-\operatorname{los}-$ tié - nen $\downarrow / /$ & 4 & $\mathrm{~A}^{1}$ \\
\hline $\begin{array}{c}\text { ó }- \text { tros }- \text { que } \uparrow / \text { por }- \text { nó }- \text { te }- \text { nér } \uparrow / / \\
\left(1^{\mathrm{a}}, 5^{\mathrm{a}}, 7^{\mathrm{a}} \text { trocaico }\right)\end{array}$ & 8 & $\mathrm{~d}$ \\
\hline $\begin{array}{c}\operatorname{con}-\mathrm{o}-\mathrm{fí}-\operatorname{cios}-\text { nó }-\mathrm{de}-\mathrm{bí}-\operatorname{dos} \uparrow / / \\
\left(3^{\mathrm{a}}, 5^{\mathrm{a}}, 7^{\mathrm{a}} \text { trocaico }\right)\end{array}$ & 8 & $\omega$ \\
\hline se $-\operatorname{man}-$ tié - nen $\downarrow\left(^{\mathrm{a}}\right)$ & 4 & A \\
\hline \multicolumn{3}{|l|}{ Copla 10} \\
\hline $\begin{array}{c}\text { Los }- \text { es }- \text { tá }- \text { dos }-y-\text { ri }- \text { qué }-\mathbf{z a} \\
\left(3^{\mathrm{a}}, 7^{\mathrm{a}} \text { trocaico }\right)\end{array}$ & 8 & $\pi$ \\
\hline $\begin{array}{l}\text { 110. que }- \text { nos }- \text { dé }- \text { xan }-a-\text { des }- \text { hó }-\mathbf{r a} \uparrow / / \\
\left(3^{\mathrm{a}}, 7^{\mathrm{a}} \text { trocaico }\right)\end{array}$ & 8 & B \\
\hline $\begin{array}{r}\text { ¿quién }- \text { lo }- \text { dú }-\mathbf{d a} ? \downarrow / / / \\
\left(1^{\mathrm{a}}, 3^{\mathrm{a}} \text { trocaico }\right)\end{array}$ & 4 & $\mathrm{C}$ \\
\hline 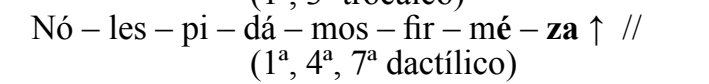 & 8 & $\mathrm{D}$ \\
\hline $\begin{array}{c}\text { Pues - que - són }- \text { de ú }- \text { na }- \text { se }-\tilde{n} \text { ń }-\mathbf{r a} \rightarrow \\
\left(3^{\mathrm{a}}, 4^{\mathrm{a}}, 7^{\mathrm{a}} \text { trocaico }\right)\end{array}$ & 8 & E \\
\hline que $-\mathrm{se}-\underset{\left(3^{\mathrm{a}}\right)}{\downarrow} \downarrow \mathbf{\text { du }}$ & 4 & $\mathrm{~F}$ \\
\hline $\begin{array}{l}\text { 115. que - bié - nes }- \text { són }- \text { de }- \text { For }- \text { tú }-\mathbf{n a} \rightarrow \\
\left(2^{\mathrm{a}}, 4^{\mathrm{a}}, 7^{\mathrm{a}} \text { mixto }\right)\end{array}$ & 8 & $\mathrm{D}$ \\
\hline $\begin{array}{c}\text { que }- \text { re }- \text { vuél }- \text { ve }- \text { con }- \text { su }- \text { rué }-\mathbf{d a} \rightarrow \\
\left(3^{\mathrm{a}}, 7^{\mathrm{a}} \text { trocaico }\right)\end{array}$ & 8 & $\mathrm{E}$ \\
\hline pre $-\mathrm{su}-$ ró $-\underset{\left(3^{\mathrm{a}}\right)}{\mathbf{s a}} \downarrow / /$ & 4 & $\mathrm{~F}$ \\
\hline $\begin{array}{c}\text { la - cual - nó - pué }- \text { de }- \text { sér }-\mathbf{u}-\mathbf{n a} \downarrow / / \\
\left(3^{\mathrm{a}}, 4^{\mathrm{a}}, 6^{\mathrm{a}}, 7^{\mathrm{a}} \text { trocaico }\right)\end{array}$ & 8 & $\mathrm{D}$ \\
\hline $\begin{array}{c}\text { ni es - tár - es -tá - ble - ni - qué }-\mathbf{d a} \uparrow / / \\
\left(2^{\mathrm{a}}, 4^{\mathrm{a}}, 7^{\mathrm{a}} \text { mixto }\right)\end{array}$ & 8 & $\mathrm{E}$ \\
\hline $\begin{array}{r}\text { 120. en }- \text { ú }- \text { na }- \text { có }-\mathbf{s a} \downarrow / / / \\
\left(2^{\mathrm{a}}, 4^{\mathrm{a}} \text { yámbico }\right)\end{array}$ & 5 & $\mathrm{~F}$ \\
\hline
\end{tabular}

\footnotetext{
${ }^{1}$ Aunque sean versos de arte menor, hemos tenido que representar la rima con letras mayúsculas dada la variedad de éstas.
} 


\section{Copla 11}

$$
\begin{aligned}
& \text { Pe - ro - dí - go - que a - com - pá - ñen } \uparrow / / \\
& \left(3^{\mathrm{a}}, 7^{\mathrm{a}} \text { trocaico }\right) \\
& \text { y - llé - guen - has - ta - la - hué - sa } \uparrow / / \\
& \left(2^{\mathrm{a}}, 7^{\mathrm{a}} \text { mixto }\right) \\
& \text { con - su - dué - ̃̃o } \downarrow / / \\
& \left(3^{\mathrm{a}}\right) \\
& \text { por - é - sso - nó - nos - en - gá - ñen } \uparrow / / \\
& \left(2^{\mathrm{a}}, 4^{\mathrm{a}}, 7^{\mathrm{a}} \text { mixto }\right) \\
& \text { 125. pues - se - vá - la - ví - da a - prié - ssa } \uparrow / / \\
& \left(3^{\mathrm{a}}, 5^{\mathrm{a}}, 7^{\mathrm{a}} \text { trocaico }\right)
\end{aligned}
$$

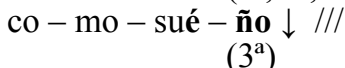

$$
\begin{aligned}
& \mathrm{Y}-\text { los - de - léi - tes - de a - cá } \uparrow / / \\
& \left(4^{\mathrm{a}}, 7^{\mathrm{a}}\right. \text { dactílico) } \\
& \text { són } \uparrow / \text { en }- \text { que }- \text { nos }- \text { de }- \text { lei }- \text { tá }-\operatorname{mos} \uparrow / / \\
& \left(1^{\mathrm{a}}, 7^{\mathrm{a}}\right. \text { dactílico) } \\
& \text { tem - po - rá - les } \downarrow \text { ( } 3^{\mathrm{a})} \\
& \text { 130. } \mathrm{y}-\text { los }- \text { tor }- \text { mén }- \text { tos }- \text { de a - llá } \uparrow / / \\
& \left(4^{\mathrm{a}}, 7^{\mathrm{a}}\right. \text { dactílico) } \\
& \text { que - por - é - llos - es - pe - rá - mos } \uparrow / / \\
& \left(3^{\mathrm{a}}, 7^{\mathrm{a}}\right. \text { trocaico) } \\
& \text { e - tér - ná - les } \downarrow / / /
\end{aligned}
$$$$
8 \quad \mathrm{G}
$$$$
8
$$$$
4
$$$$
8
$$

G

$\mathrm{H}$

I

G

$\mathrm{H}$

I

$\mathrm{J}$

$8 \quad \mathrm{y}$

4

8

$8 \quad \mathrm{y}$

4

n

\section{Copla 12}

$$
\begin{gathered}
\text { Los }- \text { pla }- \text { zé }- \text { res }-\mathrm{y}-\mathrm{dul}-\text { çó }- \text { res } \uparrow / / \\
\quad\left(3^{\mathrm{a}}, 7^{\mathrm{a}}\right. \text { trocaico) } \\
\text { dés }- \text { ta }-\mathrm{ví}-\mathrm{da}-\text { tra }- \text { ba }-\mathrm{já}-\mathbf{d a} \uparrow / / \\
\left(1^{\mathrm{a}}, 3^{\mathrm{a}}, 7^{\mathrm{a}} \text { trocaico }\right)
\end{gathered}
$$$$
\text { 135. que - te - né - mos } \uparrow / /
$$$$
\text { ¿qué - són - si - no - co - rre - dó -res } \downarrow / /
$$$$
\left(1^{\mathrm{a}}, 2^{\mathrm{a}}, 7^{\mathrm{a}} \text { mixto }\right)
$$$$
\mathrm{y}-\mathrm{la} \text { - muér - te } \uparrow / \text { - la - ce - lá - da } \rightarrow
$$$$
\left(3^{\mathrm{a}}, 7^{\mathrm{a}}\right. \text { trocaico) }
$$$$
\text { en }- \text { que }-\mathrm{ca}-\dot{\mathbf{e}}-\mathbf{m o s} \text { ? } \uparrow / / /
$$$$
\text { Nó - mi - rán - do a - nués - tro - dá - ño } \uparrow / / 8
$$$$
\left(1^{\mathrm{a}}, 3^{\mathrm{a}}, 7^{\mathrm{a}}\right. \text { trocaico) }
$$

140. co - rré - mos - a - rién - da - suél - ta $\uparrow / / \quad 8$

$$
\sin -\mathrm{pa}-\text { rár } \downarrow / /
$$$$
\left(2^{\mathrm{a}}, 5^{\mathrm{a}}, 7^{\mathrm{a}} \text { mixto }\right)
$$ 


$$
\begin{aligned}
& \text { des - que - vé - mos - el - en - gá - ̃̃o } \uparrow / / \\
& \left(3^{\mathrm{a}}, 7^{\mathrm{a}}\right. \text { trocaico) } \\
& \mathrm{y} \text { - que - ré - mos - dár - la - vuél - ta } \uparrow / / \quad 8 \\
& 3^{\mathrm{a}}, 5^{\mathrm{a}}, 7^{\mathrm{a}} \text { trocaico) } \\
& \text { nó háy - lu - gár } \downarrow / / /
\end{aligned}
$$

8

4

\section{Copla 13}

145. Si - fué - sse en - nues - tro - po - dér $\uparrow / /$

$\left(2^{\mathrm{a}}, 7^{\mathrm{a}}\right.$ mixto $)$

tor - nár - la - cá - ra - fer - mó - sa $\uparrow / / \quad 8$

cor - po - rál $\uparrow / /$

$\left(2^{\mathrm{a}}, 4^{\mathrm{a}}, 7^{\mathrm{a}}\right.$ mixto $)$

8

8

K

co - mo - po - dé - mos - ha - zér $\uparrow / /$

$\left(4^{\mathrm{a}}, 7^{\mathrm{a}}\right.$ dactílico $)$

el -á - ni - ma - glo-rï-ó-sa $\uparrow / /$

$\left(2^{\mathrm{a}}, 7^{\mathrm{a}}\right.$ mixto $)$

150. an - ge - li - cál $\downarrow / / /$

¡qué $-\mathrm{di}-\mathrm{li}-\underset{\left(1^{\mathrm{a}}, 4^{\mathrm{a}}, 7^{\mathrm{a}} \text { dactílico }\right)}{\operatorname{lia}}-\mathbf{v a} \uparrow / / \quad 8$

4

8

8

F

to - vié - ra - mos - a - tó - da - hó - ra $\uparrow / /$

8

B

$\mathrm{y}-\tan -$ prés - ta $\uparrow / /$

$\left(2,5^{a}, 7^{\mathrm{a}}\right.$ mixto)

$\left(3^{a}\right)$

en - com - po - nér - la - ca - tí $-\mathbf{v a} \downarrow / /$
$\left(4^{\mathrm{a}}, 7^{\mathrm{a}}\right.$ dactílico $)$

4

$\mathrm{N}$

8

M

155. de - xán - do - nos - la - se - ñó - ra $\rightarrow$

8

B

des - com - pués - ta $\downarrow$ ! ///

$\left.3^{\mathrm{a}}\right)$

4

$\mathrm{N}$

\section{Copla 14}
É - ssos - ré - yes - po - de - ró - sos $\uparrow / /$
$\left(1^{\mathrm{a}}, 3^{\mathrm{a}}, 7^{\mathrm{a}}\right.$ trocaico)
que - vé - mos - por - es - cri - tú - ras $\rightarrow$ $2^{\mathrm{a}}, 7^{\mathrm{a}}$ mixto))
yá - pa - ssá - das $\downarrow / /$
$\left(1^{\mathrm{a}}, 3^{\mathrm{a}}\right.$ trocaico $)$

$8 \quad \tilde{\mathrm{N}}$

8

$\mathrm{O}$

4

$\mathrm{P}$

160. con - cá - sos - trís - tes $\downarrow / 1$ lo - ró - sos $\downarrow / /$

$\left(2^{\mathrm{a}}, 4^{\mathrm{a}}, 7^{\mathrm{a}}\right.$ mixto)

fué - ron - sus - bué - nas - ven -
( $1^{\mathrm{a}}, 4^{\mathrm{a}}, 7^{\mathrm{a}}$ dactílico)

trans - tor - ná - das $\downarrow / / /$

8

$\tilde{\mathrm{N}}$

8

$\mathrm{O}$

4

P 


$$
\begin{aligned}
& \text { A - ssí - que - nó háy - có - sa - fuér -te } \uparrow / / \quad 8 \quad \text { b } \\
& \left(2^{\mathrm{a}}, 4^{\mathrm{a}}, 5^{\mathrm{a}}, 7^{\mathrm{a}} \text { mixto }\right) \\
& \text { que a - pá - pas - y em - pe - ra - dó - res } \uparrow / / \quad 8 \quad \text { r } \\
& \left(2^{\mathrm{a}}, 7^{\mathrm{a}} \text { mixto }\right) \\
& \text { 165. y - per }- \text { lá }- \text { dos } \\
& \text { a - ssí - los - trá - ta - la - muér - te } \uparrow / / \quad 8 \quad \text { b } \\
& \left(2^{\mathrm{a}}, 4^{\mathrm{a}}, 7^{\mathrm{a}} \text { mixto }\right) \\
& \text { co - mo a - los - pó - bres - pas - tó - res } \rightarrow \quad 8 \quad \text { r } \\
& \text { de - ga - ná - dos } \downarrow / / / \\
& 4^{\mathrm{a}}, 7^{\mathrm{a}} \text { dactílico) }
\end{aligned}
$$

\section{Copla 15}

$$
\begin{aligned}
& \text { De - xé - mos - a - los - tro - yá - nos } \rightarrow \\
& \text { ( } 2^{\mathrm{a}}, 7^{\mathrm{a}} \text { mixto) } \\
& \mathrm{ni}-\mathrm{sus}-\mathrm{gló}-\underset{\left(3^{\mathrm{a}}\right)}{\operatorname{rias}} \\
& \text { de }- \text { xé }- \text { mos }-\mathrm{a}-\operatorname{los}-\text { ro }- \text { má }- \text { nos } \uparrow / / \\
& \text { ( } 2^{\mathrm{a}}, 7^{\mathrm{a}} \text { mixto) } \\
& \text { aun - que o - í-mos - y - le - í - mos } \uparrow / / \\
& \text { sus - his - tó - rias } \downarrow / / / \\
& \left(3^{\mathrm{a}}, 7^{\mathrm{a}}\right. \text { trocaico) }
\end{aligned}
$$

175. Nó - cu - ré - mos - de - sa - bér $\uparrow / /$

$$
\text { qué - fué - d'é - llo } \downarrow / /
$$

$$
\begin{gathered}
\left(1^{\mathrm{a}}, 2^{\mathrm{a}}, 3^{\mathrm{a}}\right. \text { trocaico) } \\
\text { ven - gá - mos }-\mathrm{a}-\mathrm{lo}-\text { de a }- \text { yér } \downarrow / / \\
\left(2^{\mathrm{a}}, 7^{\mathrm{a}} \text { mixto }\right) \\
\text { que - tam - bién }- \text { és }- \text { ol }- \text { vi }- \text { dá }-\mathbf{d o} \uparrow / / \\
\left(3^{\mathrm{a}}, 4^{\mathrm{a}}, 7^{\mathrm{a}} \text { trocaico }\right)
\end{gathered}
$$

180. co - mo a - qué - llo $\downarrow / / /$

$$
\left(3^{\mathrm{a}}\right)
$$

4

8

d

$8 \quad \mathrm{e}$

4

$$
\mathrm{R}
$$

\section{Copla 16}
¿Qué - se - hí - zo el - rey - don - Juán? $\downarrow / / \quad 8$ $\left(1^{\mathrm{a}}, 3^{\mathrm{a}}, 7^{\mathrm{a}}\right.$ trocaico $)$$$
\text { ¿Los - in - fán - tes - de A - ra - gón } \uparrow / /
$$$$
\left(3^{\mathrm{a}}, 7^{\mathrm{a}}\right. \text { trocaico) }
$$ 


$$
\begin{aligned}
& \text { qué - se - hi - zié - ron? } \downarrow / / \quad 5 \quad \text { U } \\
& \left(1^{\mathrm{a}}, 4^{\mathrm{a}}\right) \\
& \text { ¿Qué - fué - de - tán - to - ga - lán? } \downarrow / / \quad 8 \quad \mathrm{~S} \\
& \left(1^{\mathrm{a}}, 2^{\mathrm{a}}, 4^{\mathrm{a}}, 7^{\mathrm{a}} \text { mixto }\right) \\
& \text { 185. ¿Qué - fué - de - tán - ta in - ven - ción } \uparrow / / \quad 8 \\
& \left(1^{\mathrm{a}}, 2^{\mathrm{a}}, 4^{\mathrm{a}}, 7^{\mathrm{a}} \text { mixto }\right) \\
& \text { co - mo - tru - xié - ron? } \downarrow / / / \\
& \begin{array}{c}
\text { Las }- \text { jús }- \text { tas }-\mathrm{y}-\operatorname{los}-\text { tor }- \text { né }-\mathbf{o s} \downarrow / / \\
\left(2^{\mathrm{a}}, 7^{\mathrm{a}} \text { mixto }\right)
\end{array} \\
& \text { pa - ra - mén - tos } \downarrow / \text { bor - da - dú - ras } \uparrow / / \quad 8 \\
& \left(3^{\mathrm{a}}, 7^{\mathrm{a}}\right. \text { trocaico) } \\
& \mathrm{y}-\mathrm{ci}-\mathrm{mé}-\operatorname{ras} \downarrow / / \\
& \text { 190. ¿fué - ron - si - no - de - va - né - os? } \uparrow / / \quad 8 \quad \text { V } \\
& \left(1^{\mathrm{a}}, 7^{\mathrm{a}}\right. \text { dactílico) } \\
& \text { ¿Qué - fué - ron - si - no - ver - dú - ras } \rightarrow \\
& \text { de - las - é - ras? } \downarrow / / / \\
& \left(1^{\mathrm{a}}, 2^{\mathrm{a}}, 7^{\mathrm{a}}\right. \text { mixto) }
\end{aligned}
$$

\section{Copla 17}

¿Qué - se - hi - zié - ron - las - dá - mas $\downarrow / / \quad 8 \quad$ Y $\left(1^{\mathrm{a}}, 4^{\mathrm{a}}, 7^{\mathrm{a}}\right.$ dactílico)

sus - to - cá - dos $\downarrow /$ - sus - ves - tí - dos $\downarrow / / \quad 8$ $\left(3^{\mathrm{a}}, 7^{\mathrm{a}}\right.$ trocaico)

$$
\text { 195. sus }- \text { o }- \text { ló }- \text { res? }
$$

$$
\begin{aligned}
& \text { ¿Qué - se - hi - zié - ron - las - llá - mas } \rightarrow \\
& \left(1^{\mathrm{a}}, 4^{\mathrm{a}}, 7^{\mathrm{a}}\right. \text { dactílico) }
\end{aligned}
$$

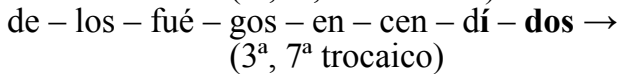

$$
\begin{aligned}
& \text { de a - ma - dó -res? } \downarrow / / /
\end{aligned}
$$

¿Qué - se - hí - zo a - quél - tro - vár $\downarrow / /$

$\left(1^{\mathrm{a}}, 3^{\mathrm{a}}, 5^{\mathrm{a}}, 7^{\mathrm{a}}\right.$ trocaico)

$\begin{array}{ccc}\text { 200. las }- \text { mú }-\mathrm{si}-\mathrm{cas}-\mathrm{a}-\mathrm{cor}-\mathrm{dá}-\mathbf{d a s} \uparrow / / & 8 & \mathrm{P} \\ \begin{array}{cc}\left(2^{\mathrm{a}}, 7^{\mathrm{a}} \text { mixto }\right) & \end{array} & \mathrm{Z}\end{array}$

$$
\begin{array}{ccc}
\text { ¿Qué }- \text { se }- \text { hí }- \text { zo a }- \text { quél }- \text { dan }- \text { çár } \downarrow / / & 8 & \text { j } \\
\left(1^{\mathrm{a}}, 3^{\mathrm{a}}, 5^{\mathrm{a}}, 7^{\mathrm{a}}\right. \text { trocaico) } & \\
\mathrm{a}-\text { qué }- \text { llas }- \text { ró }- \text { pas }- \text { cha }- \text { pá }- \text { das } \uparrow / / & 8 & \mathrm{P}
\end{array}
$$$$
\left(2^{\mathrm{a}}, 4^{\mathrm{a}}, 7^{\mathrm{a}}\right. \text { mixto) }
$$ 


\section{Copla 18}

\begin{tabular}{|c|c|}
\hline 205. Pues - el - ó - tro $\uparrow /$ su he - re - dé - ro $\uparrow / /$ & 8 \\
\hline don - En - rí - que $\uparrow / i$ Qué - po - dé - res $\uparrow / /$ & 8 \\
\hline $\mathrm{al}-\mathrm{can}-\mathrm{çá}-\mathrm{ba}$ ! $\downarrow$ / / & 4 \\
\hline $\begin{array}{c}\text { ¡cuán }- \text { blán }- \text { do } \downarrow / \text { cuán }- \text { ha }- \text { la }- \text { gué }- \text { ro } \downarrow / / \\
\left(1^{\mathrm{a}}, 2^{\mathrm{a}}, 4^{\mathrm{a}}, 7^{\mathrm{a}} \text { mixto }\right)\end{array}$ & 8 \\
\hline $\begin{array}{c}\mathrm{el}-\text { mún }-\mathrm{do}-\operatorname{con}-\operatorname{sus}-\text { pla }-\mathrm{zé}-\operatorname{res} \uparrow / / \\
\left(2^{\mathrm{a}}, 7^{\mathrm{a}} \text { mixto }\right)\end{array}$ & 8 \\
\hline 210. se - le - dá - ba! $\left(3^{\mathbf{a}}\right)$ & 4 \\
\hline 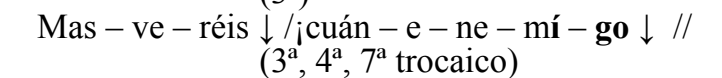 & 8 \\
\hline $\begin{array}{c}\text { cuán }- \text { con }- \text { trá }- \text { rio } \downarrow / \text { cuán }- \text { cru }- \text { él } \downarrow / / \\
\left(1^{\mathrm{a}}, 3^{\mathrm{a}}, 5^{\mathrm{a}}, 7^{\mathrm{a}} \text { trocaico }\right)\end{array}$ & 8 \\
\hline $\mathrm{se}-\mathrm{le}-\operatorname{mos}-\underset{\left(4^{\mathrm{a}}\right)}{\operatorname{tró} !} \downarrow / /$ & 5 \\
\hline $\begin{array}{c}\text { ha }- \text { bién }- \text { do }- \text { le }- \text { sí }- \text { do a }- \text { mí }- \text { go } \uparrow / / \\
\left(2^{\mathrm{a}}, 5^{\mathrm{a}}, 7^{\mathrm{a}} \text { mixto }\right)\end{array}$ & 8 \\
\hline $\begin{array}{r}\text { 215. ¡cuán - pó }- \text { co }- \text { du }- \text { ró }- \text { con }- \text { él } \uparrow / / \\
\left(1^{\mathrm{a}}, 2^{\mathrm{a}}, 5^{\mathrm{a}}, 7^{\mathrm{a}} \text { mixto }\right)\end{array}$ & 8 \\
\hline lo - que - le - dión! $\downarrow / / / /$ & 5 \\
\hline
\end{tabular}

\section{Copla 19}
Las - dá - di - vas - des - me - dí - das $\downarrow / /$ $\left(2^{\mathrm{a}}, 7^{\mathrm{a}}\right.$ mixto $)$
los $-\mathrm{e}-\mathrm{di}-\mathrm{fí}-\operatorname{cios}-\mathrm{re}-\mathbf{a}-$ les $\rightarrow$

llé - nos - de ó - ro $\downarrow / /$

G'

220. las - va - xí - llas - tan - fe - brí - das $\downarrow / /$ $\left(3^{\mathrm{a}}, 7^{\mathrm{a}}\right.$ trocaico)

los - en - rí - ques $\uparrow-\mathrm{y}-\mathrm{re}-\mathbf{a}-$ les $\rightarrow$

del - te - só - ro $\downarrow / /$

$\left(3^{\mathrm{a}}, 7^{\mathrm{a}}\right.$ trocaico)

$\left(3^{a}\right)$

G'

$$
\begin{aligned}
& \text { los }- \text { ja }- \text { é - zes } \uparrow-y-\text { ca }- \text { bá - llos } \rightarrow \\
& \left(3^{\mathrm{a}}, 7^{\mathrm{a}}\right. \text { trocaico) }
\end{aligned}
$$

H' 


$$
\begin{aligned}
& \text { de - su - gén - te } \downarrow \text { / y a- ta - ví - os } \rightarrow \quad 8 \\
& \left(3^{\mathrm{a}}, 7^{\mathrm{a}}\right. \text { trocaico) } \\
& \text { 225. tan - so - brá - dos } \uparrow / / \\
& \text { ¿dón - de i - ré - mos - a - bus - cá -llos? } \downarrow / / \quad 8 \\
& \left(1^{\mathrm{a}}, 3^{\mathrm{a}}, 7^{\mathrm{a}}\right. \text { trocaico) } \\
& \text { ¿Qué - fué - ron } \uparrow / \text { si - no - ro - cí -o } \rightarrow \quad 8 \\
& \left(1^{\mathrm{a}}, 2^{\mathrm{a}}, 7^{\mathrm{a}}\right. \text { mixto) } \\
& \text { de - los - prá - dos? } \downarrow / / / \\
& \left(3^{a}\right)
\end{aligned}
$$

\section{Copla 20}

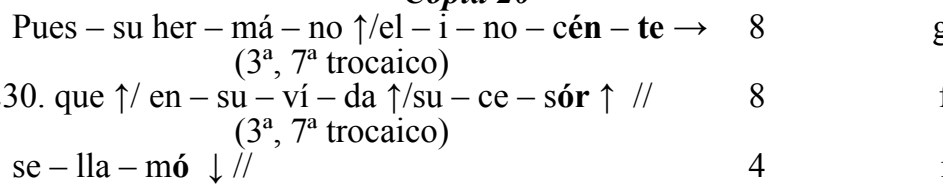

iqué - cór - te - tan - ex - ce - lén - te $\uparrow / /$

$\left(1^{\mathrm{a}}, 2^{\mathrm{a}}, 7^{\mathrm{a}}\right.$ mixto $)$

tú - vo $\downarrow / \mathrm{y}$ - cuán - to - grán - se - ñór $\rightarrow \quad 8$

$\left(1^{\mathrm{a}}, 3^{\mathrm{a}}, 5^{\mathrm{a}}, 7^{\mathrm{a}}\right.$ trocaico)

que - le - si - guió!

235. Mas $\uparrow /$ co - mo - fué - sse - mor - tál $\uparrow / /$

8

g

8

$\mathrm{f}$ $\left(4^{\mathrm{a}}, 7^{\mathrm{a}}\right.$ dactílico $)$

me - tió - le - la - muér - te - lué - go $\uparrow / /$

$\left(2^{\mathrm{a}}, 5^{\mathrm{a}}, 7^{\mathrm{a}}\right.$ mixto $)$

en - su - frá - gua $\downarrow / /$

$\left(3^{\mathrm{a}}\right)$

g

$\mathrm{f}$

i

¡Óh $\downarrow$ - ju - ï - zio - di - vi - nál! $\downarrow / /$

$\left(1^{\mathrm{a}}, 3^{\mathrm{a}}, 7^{\mathrm{a}}\right.$ trocaico)

cuan - do - más - ar - dí - a el - fué - go $\uparrow / /$

$\left(3^{\mathrm{a}}, 5^{\mathrm{a}}, 7^{\mathrm{a}}\right.$ trocaico)

240. e - chás - te á - gua $\downarrow / / /$
$\left(2^{\mathrm{a}}, 3^{\mathrm{a}}\right.$ trocaico $)$

8

8

4

$L^{\prime}$

8

$\rho$

$8 \quad \mathrm{~J}$

4

L'

\section{Copla 21}

$\begin{array}{lll}\text { Pues }-\mathrm{a}-\text { quél }- \text { grán }- \text { Con }- \text { des }- \text { tá }- \text { ble } \uparrow / / & 8 & \mathrm{~K}^{\prime} \\ \begin{array}{l}\left(3^{\mathrm{a}}, 4^{\mathrm{a}}, 7^{\mathrm{a}} \text { trocaico }\right) \\ \text { ma }- \text { és }- \text { tre }- \text { que }- \text { co }- \text { nos }- \text { cí }-\operatorname{mos} \uparrow / /\end{array} & 8 & \mathrm{x} \\ \begin{array}{l}\left(2^{\mathrm{a}}, 7^{\mathrm{a}} \text { mixto }\right) \\ \tan -\text { pri }-\mathrm{vá}-\mathbf{d o} \rightarrow / /\end{array} & 4 & \mathrm{e}\end{array}$




$$
\begin{aligned}
& \text { nó - cúm - ple - que - dél - se - há - ble } \downarrow / / \quad 8 \quad \text { K' } \\
& \left(1^{\mathrm{a}}, 2^{\mathrm{a}}, 5^{\mathrm{a}}, 7^{\mathrm{a}} \text { mixto }\right) \\
& \text { 245. si - no - só - lo - que - lo - ví - mos } \uparrow / / \\
& \text { de - go - llá - do } \downarrow / / / \\
& \left(3^{\mathrm{a}}, 7^{\mathrm{a}}\right. \text { trocaico) } \\
& \left(3^{a}\right) \\
& \text { Sus - in - fi - ní - tos - te - só - ros } \downarrow / / \\
& \left(4^{\mathrm{a}}, 7^{\mathrm{a}}\right. \text { dactílico) } \\
& \text { Sus - ví - llas - y - sus - lu - gá -res } \downarrow / / \quad 8 \quad \text { N' } \\
& \text { su - man - dár } \downarrow / / \\
& \left(2^{\mathrm{a}}, 7^{\mathrm{a}}\right. \text { mixto) } \\
& 8 \quad \mathrm{x} \\
& 4 \\
& 8 \\
& \text { M' } \\
& \left(3^{a}\right) \\
& \text { 250. ¿qué - le - fué - ron - si - no - lló - ros? } \downarrow / / \\
& \left(1^{\mathrm{a}}, 3^{\mathrm{a}}, 7^{\mathrm{a}}\right. \text { trocaico) } \\
& \text { ¿fué }- \text { ron }- \text { le }-\mathrm{si}-\text { no }- \text { pe }-\mathrm{sa} \\
& \text { al - de - xár? } \uparrow / / /
\end{aligned}
$$

\section{Copla 22}

Pues - los - ó - tros - dós - her - má - nos $\uparrow / /$

$$
\begin{aligned}
& \left(3^{\mathrm{a}}, 5^{\mathrm{a}}, 7^{\mathrm{a}} \text { trocaico }\right) \\
\mathrm{ma}-\text { és }-\operatorname{tres}-\tan -\text { pros }- \text { pe }- \text { rá }-\operatorname{dos} \rightarrow & \left(2^{\mathrm{a}}, 7^{\mathrm{a}} \text { mixto }\right)
\end{aligned}
$$

255. co - mo - ré - yes

que a - los - grán $-\operatorname{des}-\mathrm{y}-\mathrm{me}-\operatorname{diá}-\operatorname{nos} \uparrow / / \quad 8$

$\left(3^{\mathrm{a}}, 7^{\mathrm{a}}\right.$ trocaico)

tru - xé - ron - tan - so - juz - gá - dos $\rightarrow / /$

$\left(2^{\mathrm{a}}, 7^{\mathrm{a}}\right.$ mixto)

a - sus - lé - yes $\downarrow / / /$

$\mathrm{a}$ - qué - lla - pros - pe - ri - dád $\rightarrow$

$\left(2^{\mathrm{a}}, 7^{\mathrm{a}}\right.$ mixto $)$

260. que - tan - ál - to - fué - su - bí - da $\uparrow / /$ $\left(3^{\mathrm{a}}, 5^{\mathrm{a}}, 7^{\mathrm{a}}\right.$ trocaico)

y en - sal - zá - da $\downarrow / /$

$\tilde{\mathrm{n}}$

8

$\delta$

4

$\tilde{\mathrm{N}}^{\prime}$

n

$8 \quad \delta$

4

8

$\tilde{\mathrm{N}}^{\prime}$

$\mathrm{t}$

8

a

4

$\mathrm{v}$

¿qué - fue - si - no - cla - ri - dád $\rightarrow$

$\left(1^{\mathrm{a}}, 2^{\mathrm{a}}, 7^{\mathrm{a}}\right.$ mixto)

que $\uparrow /$ es - tán - do - más - en - cen - dí - da $\uparrow / / \quad 8$ $\left(3^{\mathrm{a}}, 5^{\mathrm{a}}, 7^{\mathrm{a}}\right.$ trocaico)

fué a - ma - tá - da? $\downarrow / / /$

$\left(1^{\mathrm{a}}, 3^{\mathrm{a}}\right.$ trocaico) 


\section{Copla 23}

\begin{tabular}{|c|c|}
\hline $\begin{array}{l}\text { 265. Tán }- \text { tos }- \text { dú }- \text { ques }- \text { ex }- \text { ce }- \text { lén }- \text { tes } \downarrow / / \\
\qquad\left(1^{\mathrm{a}}, 3^{\mathrm{a}}, 7^{\mathrm{a}} \text { trocaico }\right) \\
\text { tán }- \text { tos }-\operatorname{mar}-\text { qué }- \text { ses }-\mathrm{y}-\text { cón }- \text { des } \downarrow / / \\
\left(1^{\mathrm{a}}, 4^{\mathrm{a}}, 7^{\mathrm{a}} \text { dactílico }\right)\end{array}$ & 8 \\
\hline $\mathrm{y}-\mathrm{ba}-\mathrm{ró}-\underset{\left(3^{\mathrm{a}}\right)}{\downarrow} / /$ & 4 \\
\hline co - mo - ví $-\operatorname{mos}_{\left(3^{\mathrm{a}}, 7^{\mathrm{a}} \text { trocaico }\right)} \tan -$ tén - tes $\downarrow / /$ & 8 \\
\hline $\begin{array}{c}\text { dí } \downarrow / \text { muér }- \text { te } \downarrow / \text { idó- los }- \text { es }- \text { cón }- \text { des } \uparrow / / \\
\left(1^{\mathrm{a}}, 2^{\mathrm{a}}, 4^{\mathrm{a}}, 7^{\mathrm{a}} \text { mixto }\right)\end{array}$ & 8 \\
\hline 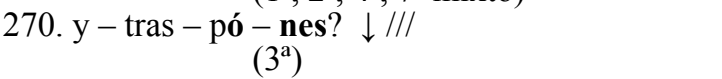 & 4 \\
\hline $\begin{array}{c}\mathrm{Y}-\text { las }- \text { sus }- \text { clá }- \text { ras }- \text { ha }- \text { zá }-\tilde{\mathbf{n a s}} \rightarrow \\
\left(4^{\mathrm{a}}, 7^{\mathrm{a}} \text { dactílico }\right)\end{array}$ & 8 \\
\hline $\begin{array}{c}\text { Que }- \text { hi }- \text { zié }- \text { ron }- \text { en }- \text { las }- \text { gué }-\operatorname{rras} \uparrow / / \\
\left(3^{\mathrm{a}}, 7^{\mathrm{a}} \text { trocaico }\right)\end{array}$ & 8 \\
\hline y en - las - pá $-\mathbf{z e s} \downarrow / /$ & 4 \\
\hline $\begin{array}{c}\text { cuan }- \text { do }- \text { tú } \uparrow / \text { crú }- \text { da } \uparrow / \text { te en }- \text { sá }-\tilde{\text { nas }} \uparrow / / \\
\left(3^{\mathrm{a}}, 4^{\mathrm{a}}, 7^{\mathrm{a}} \text { trocaico }\right)\end{array}$ & 8 \\
\hline $\begin{array}{l}\text { 275. con }- \text { tu }- \text { fuér }- \text { ça }- \text { las }-\mathrm{a}-\text { tié }-\operatorname{rras} \uparrow / / \\
\qquad\left(3^{\mathrm{a}}, 7^{\mathrm{a}} \text { trocaico }\right)\end{array}$ & 8 \\
\hline $\mathrm{y}-\operatorname{des}-$ há $-\underset{\left(3^{\mathrm{a}}\right)}{\mathbf{z e s}} \mathfrak{l / /}$ & 4 \\
\hline
\end{tabular}

\section{Copla 24}

Las - hués - tes - in - nu - me - rá - bles $\downarrow / /$ $\left(2^{\mathrm{a}}, 7^{\mathrm{a}}\right.$ mixto)

los - pen - dó - nes - y es - tan - dár - tes $\downarrow / / \quad 8$ $\left(3^{\mathrm{a}}, 7^{\mathrm{a}}\right.$ trocaico)

$\mathrm{y}$ - ban - dé - ras $\downarrow / /$

280. los - cas - tí - llos - im - pug - ná - bles $\downarrow / /$

$\mathrm{T}^{\prime}$ $\left(3^{\mathrm{a}}, 7^{\mathrm{a}}\right.$ trocaico)

los - mú - ros $-\mathrm{y}-\mathrm{ba}-\mathrm{lu}-$

$\mathrm{y}-\mathrm{ba}-$ rré - ras $\downarrow / /$

la - cá - va - hón - da $\downarrow /$ cha - pá - da $\downarrow / /$ $\left(2^{\mathrm{a}}, 4^{\mathrm{a}}, 7^{\mathrm{a}}\right.$ mixto $)$

o - cual - quiér - ó - tro - re - pá - ro $\downarrow / /$ $\left(3^{\mathrm{a}}, 4^{\mathrm{a}}, 7^{\mathrm{a}}\right.$ trocaico)

285. ¿Qué a - pro - vé - cha? $\downarrow / /$ 


$$
\begin{aligned}
& \left(1^{\mathrm{a}}, 3^{\mathrm{a}}\right. \text { trocaico) } \\
& \text { Que - si - tú - vié - nes - ai - rá - da } \uparrow / / \quad 8 \quad \text { v } \\
& \left(3^{\mathrm{a}}, 4^{\mathrm{a}}, 7^{\mathrm{a}}\right. \text { trocaico) } \\
& \text { tó - do - lo - pá - ssas - de - clá - ro } \uparrow / / \quad 8 \quad \text { Y' } \\
& \left(1^{\mathrm{a}}, 4^{\mathrm{a}}, 7^{\mathrm{a}} \text { dactílico }\right) \\
& \text { con - tu - flé - cha } \downarrow / / / \\
& \left(3^{\mathrm{a}}\right)
\end{aligned}
$$

\section{Copla 25}

$$
\begin{aligned}
& \text { A - quél } \uparrow / \text { de - bué }- \text { nos }-\mathrm{a}-\text { brí }- \text { go } \uparrow / / \quad 8 \quad \text { D' } \\
& \left(2^{\mathrm{a}}, 4^{\mathrm{a}}, 7^{\mathrm{a}} \text { mixto }\right) \\
& \begin{array}{l}
\text { 290. a- má - do }- \text { por }- \text { vir }- \text { tu }-\mathbf{o}-\mathbf{s o} \rightarrow \\
\left(2^{\mathrm{a}}, 7^{\mathrm{a}} \text { mixto }\right)
\end{array} \\
& \text { de } \left.- \text { la - gén - te } \downarrow \text { ( } 3^{\text {a }}\right) \text { // } \\
& \text { el - ma - és - tre - don - Ro - drí - go } \rightarrow \\
& \left(3^{\mathrm{a}}, 7^{\mathrm{a}}\right. \text { trocaico) } \\
& \text { Man - rí - que } \uparrow / \tan -\text { fa }- \text { mó - so } \uparrow / / \quad 7 \text { A" } \\
& \left(2^{\mathrm{a}}, 6^{\mathrm{a}} \text { yámbico }\right) \\
& \mathrm{y}-\tan -\mathrm{va}-\text { lién - te } \downarrow / / /
\end{aligned}
$$

\section{Copla 26}

¡Qué a - mí - go - de - sus - a - mí - gos! $\downarrow / / \quad 8 \quad$ D”

$$
\left(1^{\mathrm{a}}, 2^{\mathrm{a}}, 7^{\mathrm{a}} \text { mixto }\right)
$$

¡Qué - se - ñór - pa - ra - cri - á - dos $\uparrow / / \quad 8$ $\left(1^{\mathrm{a}}, 3^{\mathrm{a}}, 7^{\mathrm{a}}\right.$ trocaico)

$$
\mathrm{y}-\mathrm{pa}-\text { rién - tes! } \downarrow / /
$$

¡Qué e - ne - mí - go - de e - ne - mí - gos! $\downarrow / / \quad 8$

$\left(1^{\mathrm{a}}, 3^{\mathrm{a}}, 7^{\mathrm{a}}\right.$ trocaico $)$

305.iQué - ma - és - tro - de es - for - çá - dos $\uparrow / / 8$ $\left(1^{\mathrm{a}}, 3^{\mathrm{a}}, 7^{\mathrm{a}}\right.$ trocaico)

D” 


$$
\begin{aligned}
& \text { y - va - lién - tes! } \downarrow / / \\
& \left(3^{a}\right) \\
& \text { ¡Qué - sé - so - pa - ra - dis - cré - tos! } \downarrow / / \quad 8 \\
& \left(1^{\mathrm{a}}, 2^{\mathrm{a}}, 7^{\mathrm{a}}\right. \text { mixto) } \\
& \text { ¡Qué - grá - cia - pa - ra - do - nó - sos! } \downarrow / / \quad 8 \\
& \left(1^{\mathrm{a}}, 2^{\mathrm{a}}, 7^{\mathrm{a}}\right. \text { mixto) } \\
& \text { ¡Qué - ra-zón! } \\
& \left(1^{\mathrm{a}}, 3^{\mathrm{a}}\right. \text { trocaico) } \\
& \left(1^{\mathrm{a}}, 3^{\mathrm{a}}\right. \text { trocaico) }
\end{aligned}
$$

E”

$\tilde{N}$

$\mathrm{T}$

\section{Copla 27}

$$
\begin{aligned}
& \text { En - ven - tú - ra } \uparrow / \text { Oc - ta - vï - á - no } \downarrow / / \\
& \left(3^{\mathrm{a}}, 7^{\mathrm{a}}\right. \text { tocaico) } \\
& \text { Jú - lio - Cé - sar } \uparrow / \text { en - ven - cér } \uparrow / / \quad 8 \\
& \text { 315. y - ba - ta - llár } \downarrow / / \\
& \left(1^{\mathrm{a}}, 3^{\mathrm{a}}, 7^{\mathrm{a}}\right. \text { trocaico) }
\end{aligned}
$$

$$
\begin{gathered}
\text { en }- \text { la }- \text { vir }- \text { túd } \uparrow / \text { A - fri }- \text { cá }- \text { no } \downarrow / / \\
\left(4^{\mathrm{a}}, 7^{\mathrm{a}} \text { dactílico }\right) \\
\mathrm{A}-\mathrm{ní}-\text { bal } \uparrow / \text { en }- \text { el }- \text { sa }- \text { bér } \uparrow / / \\
\left(2^{\mathrm{a}}, 7^{\mathrm{a}} \text { mixto }\right)
\end{gathered}
$$$$
\mathrm{y}-\text { tra - ba - jár }
$$

$$
\text { en - la - bon - dád } \uparrow / \text { ún - Tra - já - no } \downarrow / /
$$$$
\text { ( } 4^{\mathrm{a}}, 5^{\mathrm{a}}, 7^{\mathrm{a}} \text { dactílico) }
$$

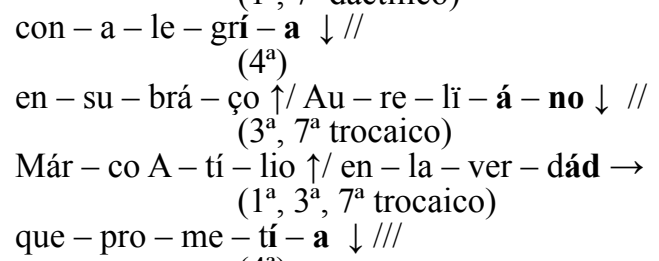
en - su - brá - ço $\uparrow / \mathrm{Au}-\mathrm{re}-\mathrm{lï}-\mathbf{a}-$ no $\downarrow / /$ $\left(3^{\mathrm{a}}, 7^{\mathrm{a}}\right.$ trocaico)
Már - co A - tí - lio $\uparrow /$ en - la - ver - dád $\rightarrow$ $\left(1^{\mathrm{a}}, 3^{\mathrm{a}}, 7^{\mathrm{a}}\right.$ trocaico $)$

\section{Copla 28}

325. An - tó - nio - Pí - o $\uparrow /$ en - cle - mén - cia $\downarrow / / 8$ 


$$
\begin{aligned}
& \text { Már - co Au - ré -lio } \uparrow / \text { en - i - gual - dád } \rightarrow \quad 8 \quad \text { t } \\
& \left(1^{\mathrm{a}}, 3^{\mathrm{a}}, 7^{\mathrm{a}}\right. \text { trocaico) } \\
& \text { del - sem - blán - te } \downarrow / / \\
& \left(4^{\mathrm{a}}\right) \\
& \mathrm{A}-\mathrm{drï}-\mathrm{a}-\text { no } \uparrow / \text { en }-\mathrm{e}-\mathrm{lo}-\text { cuén }- \text { cia } \downarrow / / \quad 8 \quad \mathrm{H} \text { ” } \\
& \left(3^{\mathrm{a}}, 7^{\mathrm{a}}\right. \text { trocaico) } \\
& \text { Teo - dó - sio } \uparrow / \text { en - hu - má - ni - dád } \uparrow / / \quad 8 \quad \mathrm{t} \\
& \text { 330. y - buén - ta - lán - te } \downarrow / / \\
& \text { ( } \left.2^{\mathrm{a}}, 4^{\mathrm{a}} \text { yámbico }\right) \\
& \mathrm{Au} \text { - ré - lio A - le - xán - dre - fué } \uparrow / / \quad 8 \quad \text { z } \\
& \left(2^{\mathrm{a}}, 5^{\mathrm{a}}, 7^{\mathrm{a}} \text { mixto }\right) \\
& \text { en - dis - ci - plí - na y - ri - gór } \rightarrow \\
& \text { (4a }, 7^{\mathrm{a}} \text { dactílico) } \\
& \text { de - la - gué - rra } \downarrow / / \\
& \left(3^{\mathrm{a}}\right) \\
& \begin{array}{c}
\text { ún }- \text { Cons }-\tan -\text { tí }- \text { no } \uparrow / \text { en }- \text { la }- \text { fé } \downarrow / / \\
\left(1^{\mathrm{a}}, 4^{\mathrm{a}}, 7^{\mathrm{a}} \text { dactílico }\right)
\end{array} \\
& 4 \\
& \text { I' } \\
& \text { I" } \\
& \left(2^{\mathrm{a}}, 5^{\mathrm{a}}, 7^{\mathrm{a}}\right. \text { mixto) } \\
& \text { 335. Ca - mí - lo } \uparrow / \text { en - el - grán - a - mór } \rightarrow \\
& \mathrm{de}-\mathrm{su}-\text { tié- rra } \downarrow / / / \\
& \left(3^{\mathrm{a}}\right)
\end{aligned}
$$




$$
\begin{aligned}
& \text { las - rén - tas - 个y - los - va - sá - llos } \rightarrow \quad 8 \quad \text { U } \\
& \left(2^{a}, 7^{a} \text { mixto }\right) \\
& \left(3^{a}\right)
\end{aligned}
$$

\section{Copla 30}

$$
\begin{aligned}
& \text { Pues - por - su - hón - ra - y es - tá - do } \uparrow / / \quad 8 \\
& \left(3^{\mathrm{a}}, 7^{\mathrm{a}}\right. \text { trocaico) } \\
& \text { 350. en - ó - tros - tiém - pos - pa - ssá - dos } \uparrow / / \\
& \left(2^{\mathrm{a}}, 4^{\mathrm{a}}, 7^{\mathrm{a}} \text { mixto }\right) \\
& \text { ¿Có - mo - se hú - bo? } \downarrow / / \\
& \left(1^{\mathrm{a}}, 3^{\mathrm{a}}\right. \text { trocaico) } \\
& \text { Que - dán - do - de - sam - pa - rá - do } \uparrow / / \quad 8 \\
& \left(2^{\mathrm{a}}, 7^{\mathrm{a}}\right. \text { mixto) } \\
& \text { con - her - má - nos - y - cri - á - dos } \uparrow / / \quad 8 \\
& \left(3^{\mathrm{a}}, 7^{\mathrm{a}}\right. \text { trocaico) } \\
& \text { se - sos - tú - vo } \downarrow / / /
\end{aligned}
$$

\section{Copla 31}

$$
\begin{aligned}
& \text { És - tas - sus - vié - jas - es - tó -rias } \rightarrow \quad 8 \\
& \left(1^{\mathrm{a}}, 4^{\mathrm{a}}, 7^{\mathrm{a}}\right. \text { dactílico) } \\
& \text { que }- \text { con }- \text { su }- \text { brá }- \text { ço }- \text { pin - tó } \uparrow / / \\
& \left(4^{\mathrm{a}}, 7^{\mathrm{a}}\right. \text { dactílico) } \\
& \text { en }- \text { la }- \text { jo-ven }- \text { túd } \uparrow / / \\
& \text { con - ó - tras - nué - vas - vic - tó - rias } \uparrow / / \\
& \left(2^{\mathrm{a}}, 4^{\mathrm{a}}, 7^{\mathrm{a}} \text { mixto }\right) \\
& \begin{aligned}
& 365 . \mathrm{a}-\text { gó }-\mathrm{ra}- \text { las }-\mathrm{re}-\text { no }- \text { vó } \uparrow / / \\
&\left(2^{\mathrm{a}}, 7^{\mathrm{a}} \text { mixto }\right)
\end{aligned}
\end{aligned}
$$




$$
\begin{aligned}
& \text { Por - su - grán - ha - bi - li - dád } \downarrow / / \quad 3 \quad \mathrm{t} \\
& \left(3^{\mathrm{a}}, 7^{\mathrm{a}}\right. \text { trocaico) } \\
& \text { por - mé - ri - tos - } \text { y an - cia - ní - a } \rightarrow \\
& \left(2^{\mathrm{a}}, 7^{\mathrm{a}} \text { mixto }\right) \\
& \text { bién - gas - tá - da } \uparrow / / \\
& \left(1^{\mathrm{a}}, 3^{\mathrm{a}} \text { trocaico }\right) \\
& \text { 370. al - can - çó - la - dig - ni-dád } \uparrow / / \\
& 8 \quad \mathrm{G}^{\prime \prime} \\
& 4 \\
& 8 \\
& \text { de - la - grán - ca - ba - lle - rí -a } \rightarrow \\
& \left(3^{\mathrm{a}}, 7^{\mathrm{a}}\right. \text { trocaico) } \\
& \text { de - la Es - pá - da } \downarrow / / / \\
& \left(3^{\mathrm{a}}\right) \\
& \mathrm{V}
\end{aligned}
$$

\begin{tabular}{|c|c|}
\hline $\begin{array}{c}\text { 380. si-de - las }- \text { ó }- \text { bras }- \text { que o }- \text { bró } \uparrow / / \\
\left(4^{\mathrm{a}}, 7^{\mathrm{a}} \text { dactílico }\right)\end{array}$ & 8 \\
\hline fué - ser - ví $-\mathbf{d o} \downarrow / / /$ & 4 \\
\hline $\begin{array}{c}\text { dí }- \text { ga }- \text { lo el }- \text { de }- \text { Por }- \text { tu }- \text { gál } \uparrow / / \\
\left(1^{\mathrm{a}}, 7^{\mathrm{a}} \text { dactílico }\right)\end{array}$ & 8 \\
\hline $\begin{array}{c}\text { y en }- \text { Cas }- \text { tí }-11 \mathrm{a}-\text { quien }-\mathrm{si}-\text { guió } \uparrow / / \\
\left(3^{\mathrm{a}}, 7^{\mathrm{a}} \text { trocaico }\right)\end{array}$ & 8 \\
\hline $\mathrm{su}-\mathrm{par}-\mathrm{tí}-\mathbf{d o} \downarrow / / / /$ & 4 \\
\hline
\end{tabular}

Copla 32

$$
\begin{array}{ccc}
\mathrm{Y}-\mathrm{sus}-\mathrm{ví}-\operatorname{llas}-\mathrm{y}-\mathrm{sus}-\text { tié }- \text { rras } \uparrow / / & 8 & \mathrm{R}^{\prime} \\
\left(3^{\mathrm{a}}, 7^{\mathrm{a}}\right. \text { trocaico) } & & \\
\mathrm{o}-\mathrm{cu}-\mathrm{pá}-\mathrm{das}-\mathrm{de}-\mathrm{ti}-\mathrm{rá}-\mathbf{n o s} \uparrow / / & 8 & \tilde{\mathrm{n}}
\end{array}
$$$$
\text { 375. las - ha - lló } \downarrow / /
$$$$
\left(3^{\mathrm{a}}, 7^{\mathrm{a}} \text { trocaico }\right)
$$

$$
\begin{gathered}
\text { mas - por - cér }-\cos -\mathrm{y}-\text { por }- \text { gué }- \text { rras } \downarrow / / \\
\left(3^{\mathrm{a}}, 7^{\mathrm{a}}\right. \text { tocaico) }
\end{gathered}
$$

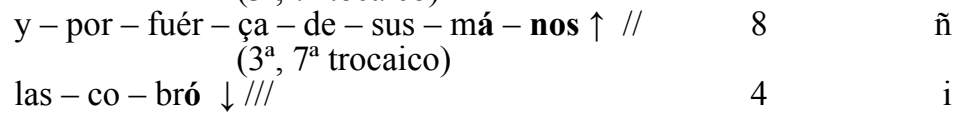

Pues - nues - tro - réy - na - tu - rál $\uparrow / /$

$$
\text { (4, } 7^{\mathrm{a}} \text { dactílico) }
$$

\section{Copla 33}
385. Des - pués - de - pués - ta - la - ví - da $\uparrow / / \quad 8$ $\left(2^{\mathrm{a}}, 4^{\mathrm{a}}, 7^{\mathrm{a}}\right.$ mixto $)$

$$
\left(1^{\mathrm{a}}, 3^{\mathrm{a}}, 7^{\mathrm{a}}\right. \text { trocaico) }
$$$$
\text { tán - tas - vé - zes - por - su - léy } \uparrow / /
$$ 


$$
\begin{aligned}
& \text { al - ta - blé - ro } \downarrow / / \quad 4 \quad A^{\prime} \\
& \text { des - pués - de - tan - bién - ser - ví - da } \uparrow / / \quad 8 \\
& \left(2^{\mathrm{a}}, 5^{\mathrm{a}}, 7^{\mathrm{a}} \text { mixto }\right) \\
& \text { la - co - ró - na - de - su - réy } \rightarrow \\
& \left(3^{\mathrm{a}}, 7^{\mathrm{a}} \text { trocaico }\right) \\
& \text { 390. ver - da - dé - ro } \downarrow / / \\
& \text { des - pués - de - tán - ta - ha - zá - ña } \rightarrow \\
& \left(2^{\mathrm{a}}, 4^{\mathrm{a}}, 7^{\mathrm{a}} \text { mixto }\right) \\
& \text { a - que - nó - pué - de - bas - tár } \uparrow / / \\
& \left(3^{\mathrm{a}}, 4^{\mathrm{a}}, 7^{\mathrm{a}} \text { trocaico }\right) \\
& \text { cuén }- \text { ta }- \text { ciér }- \text { ta } \downarrow / / \\
& \left(1^{\mathrm{a}}, 3^{\mathrm{a}}\right. \text { trocaico) } \\
& \text { en - la - su - ví - lla - de O - cá - ̃̃a } \uparrow / / \quad 8 \\
& \left(4^{\mathrm{a}}, 7^{\mathrm{a}} \text { dactílico }\right)
\end{aligned}
$$

\section{Copla 34}

$$
\begin{aligned}
& \text { Di - zién - do } \downarrow / \text { "Buén - ca - ba - llé - ro } \downarrow / / \\
& \left(2^{\mathrm{a}}, 4^{\mathrm{a}}, 7^{\mathrm{a}} \text { mixto }\right) \\
& \text { de - xád - el - mún - do en - ga - ñó - so } \uparrow / / \\
& \left(2^{\mathrm{a}}, 4^{\mathrm{a}}, 7^{\mathrm{a}} \text { mixto }\right) \\
& \mathrm{y}-\mathrm{su} \text { - ha - lá - go }
\end{aligned}
$$

400. vues - tro - co - ra - çón - de a - zé - ro $\uparrow / /$

$\left(5^{\mathrm{a}}, 7^{\mathrm{a}}\right.$ trocaico $)$

$$
\begin{aligned}
& \text { mués - tre - su es - fuér - ço - fa - mó - so } \uparrow / / \\
& \left(1^{\mathrm{a}}, 4^{\mathrm{a}}, 7^{\mathrm{a}}\right. \text { dactílico) }
\end{aligned}
$$

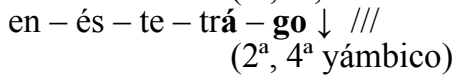

$$
\begin{aligned}
& \text { y - pues - de - ví - da y - sa - lúd } \uparrow / / \\
& \left(4^{\mathrm{a}} .7^{\mathrm{a}}\right. \text { dactílico) } \\
& \text { he - zís - tes - tan - pó - ca - cuén - ta } \uparrow / / \\
& \left(2^{\mathrm{a}}, 5^{\mathrm{a}}, 7^{\mathrm{a}} \text { mixto }\right) \\
& \text { 405. por - la - fá - ma } \uparrow / /
\end{aligned}
$$$$
\text { es - for - çád - vues - tra - vir - túd } \uparrow / /
$$$$
\left(3^{\mathrm{a}}, 7^{\mathrm{a}}\right. \text { trocaico) }
$$$$
\text { pa - ra - so - frír - és - ta a - fruén - ta } \rightarrow
$$$$
\left(4^{\mathrm{a}}, 5^{\mathrm{a}}, 7^{\mathrm{a}} \text { dactílico }\right)
$$ 


$$
\text { que os - 1lá }-\underset{\left(2^{\mathrm{a}}\right)}{\mathbf{m a}} \downarrow / / /
$$

$\mathrm{R} ”$

\section{Copla 35}

$$
\begin{gathered}
\text { Nó }- \text { se os }- \text { há }- \text { ga }-\tan -\mathrm{a}-\operatorname{már}-\mathbf{g a} \uparrow / / \\
\left(1^{\mathrm{a}}, 3^{\mathrm{a}}, 7^{\mathrm{a}} \text { trocaico }\right)
\end{gathered}
$$

$$
\begin{gathered}
\left(3^{\mathrm{a}}, 7^{\mathrm{a}}\right. \text { trocaico) } \\
\text { que es }- \text { pe }- \text { ráis } \downarrow / / \\
\left(3^{\mathrm{a}}\right)
\end{gathered}
$$

$$
\begin{gathered}
\text { pues }- \text { ó }- \text { tra }- \text { ví }- \text { da }- \text { más }- \text { lár }-\mathbf{g a} \uparrow / / \\
\left(2^{\mathrm{a}}, 4^{\mathrm{a}}, 6^{\mathrm{a}}, 7^{\mathrm{a}} \text { mixto }\right)
\end{gathered}
$$$$
\text { de }- \text { fá - ma - tan - glo - rï - ó - sa } \uparrow / /
$$

$$
\mathrm{a}-\text { cá }-\mathrm{de}-\text { xáis } \downarrow \text { /// }
$$

$\left(2^{\mathrm{a}}, 4^{\mathrm{a}}\right.$ yámbico $)$
415. Aun - que és - ta - ví - da - de ho - nór $\uparrow / / 8$
$\left(2^{\mathrm{a}}, 4^{\mathrm{a}}, 7^{\mathrm{a}}\right.$ mixto)

$$
\begin{gathered}
\text { tam }- \text { pó - co - nó és }-\mathrm{e}-\text { ter }- \text { nál } \uparrow / / \\
\left(2^{\mathrm{a}}, 4^{\mathrm{a}}, 7^{\mathrm{a}} \text { mixto }\right)
\end{gathered}
$$$$
\text { ni - ver - da - dé - ra } \downarrow / /
$$

$$
\begin{gathered}
\text { mas }- \text { con }- \text { tó }- \text { do és }- \text { muý }- \text { me }- \text { jór } \uparrow / / \\
\quad\left(3^{\mathrm{a}}, 4^{\mathrm{a}}, 5^{\mathrm{a}}, 7^{\mathrm{a}} \text { trocaico }\right) \\
\text { que }- \text { la }- \text { ó }- \text { tra }- \text { tem }- \text { po }- \text { rál } \downarrow / / \\
\left(3^{\mathrm{a}}, 7^{\mathrm{a}} \text { trocaico }\right) \\
\begin{array}{c}
\text { 420. pe }- \text { res }- \text { ce }- \text { dé }- \text { ra } \downarrow / / / /
\end{array}
\end{gathered}
$$

\section{Copla 36}

$$
\begin{aligned}
& \mathrm{El} \text { - vi - vír - que és - per - du - rá - ble } \uparrow / / \quad 8 \quad \text { K' } \\
& \left(3^{\mathrm{a}}, 4^{\mathrm{a}}, 7^{\mathrm{a}} \text { trocaico }\right) \\
& \text { Nó - se - gá - na - con - es - tá - dos } \rightarrow \quad 8 \quad \delta \\
& \text { mun - da - ná - les } \downarrow / / \\
& \left(3^{\mathrm{a}}\right) \\
& \mathrm{ni}-\mathrm{con}-\mathrm{ví}-\mathrm{da}-\mathrm{de}-\text { lei - tá - ble } \uparrow / / \\
& \left(3^{\mathrm{a}}, 7^{\mathrm{a}}\right. \text { trocaico) } \\
& \text { 425. en - que - mó - ran - los - pe - cá - dos } \rightarrow \\
& \left(3^{\mathrm{a}}, 7^{\mathrm{a}}\right. \text { trocaico) } \\
& \text { in - fer - ná - les } \\
& \text { Mas - los - bué - nos - re - li - gió - sos } \uparrow / / \\
& 4 \\
& \mathrm{n} \\
& 8 \\
& \mathrm{~K}^{\prime} \\
& 8 \\
& \delta
\end{aligned}
$$$$
\left(3^{\mathrm{a}}, 7^{\mathrm{a}}\right. \text { trocaico) }
$$ 


$$
\begin{aligned}
& \text { gá - nan - lo - con - o - ra - ció - nes } \uparrow / / \quad 8 \quad \mathrm{p} \\
& \mathrm{y}-\operatorname{con}-1 \text { ó }-\operatorname{ros} \downarrow / / \\
& \left(3^{\mathrm{a}}\right) \\
& \text { 430. los - ca - ba - llé - ros - fa - mó - sos } \uparrow / / \quad 8 \\
& \left(4^{\mathrm{a}}, 7^{\mathrm{a}}\right. \text { dactílico) } \\
& \text { con - tra - bá - jos - y a - flic - ció - nes } \uparrow / / \quad 8 \\
& \left(3^{\mathrm{a}}, 7^{\mathrm{a}} \text { trocaico }\right) \\
& \text { con - tra - mó - ros } \downarrow / / / \\
& \left(3^{\mathrm{a}}\right)
\end{aligned}
$$

\section{Copla 37}

$$
\begin{gathered}
\mathrm{Y}-\text { pues }- \text { vós } \downarrow / \text { clá }- \text { ro }- \text { va }- \text { rón } \downarrow / / \\
\left(3^{\mathrm{a}}, 4^{\mathrm{a}}, 7^{\mathrm{a}}\right. \text { trocaico) } \\
\text { tán }- \text { ta }- \text { sán }- \text { gre }- \text { de }- \text { rra }- \text { más }- \text { tes } \uparrow / / \\
\left(1^{\mathrm{a}}, 3^{\mathrm{a}}, 7^{\mathrm{a}} \text { trocaico }\right) \\
\begin{array}{c}
\text { 435. de }- \text { pa }- \text { gá }- \text { nos } \uparrow / / \\
\left(3^{\mathrm{a}}\right)
\end{array} \\
\text { es }- \text { pe }- \text { rád }-\mathrm{el}-\mathrm{ga}-\text { lar }- \text { dón } \rightarrow
\end{gathered}
$$

$$
\begin{aligned}
& \text { por - las - má - nos } \downarrow / / / \\
& \left(3^{a}\right) \\
& \text { y - con - és - ta - con - fián - ça } \downarrow / /
\end{aligned}
$$

\section{Copla 38}

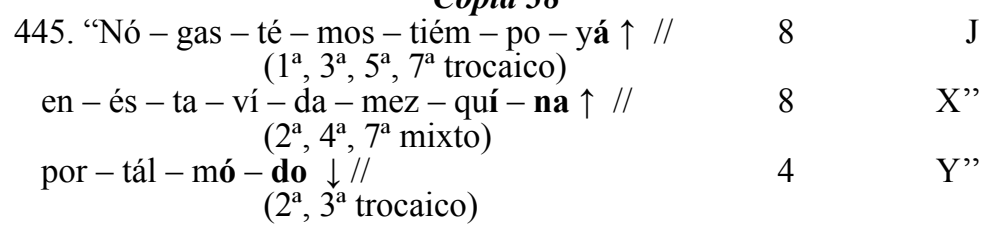




$$
\begin{aligned}
& \text { que - mi - vo - lun - tád - es - tá } \uparrow / / \quad 8 \quad J \\
& \left(5^{\mathrm{a}}, 7^{\mathrm{a}} \text { trocaico }\right) \\
& \text { con - fór - me - con - la - di - ví - na } \uparrow / / \quad 8 \quad \text { X” } \\
& \text { 450. pa - ra - tó - do } \downarrow / / / 4 \text { Y" } \\
& \left(3^{\mathrm{a}}\right) \\
& \mathrm{y}-\text { con - sién - to en }-\mathrm{mi}-\mathrm{mo}-\text { rír } \uparrow / / \quad 8 \quad \mathrm{~m} \\
& \left(3^{\mathrm{a}}, 7^{\mathrm{a}}\right. \text { trocaico) } \\
& \text { con - vo - lun - tád - pla - zen - té - ra } \downarrow / / \quad 8 \quad \text { k } \\
& \text { clá - ra y - pú - ra } \downarrow / / / 4 \\
& \left(1^{a}, 3^{a}\right. \text { trocaico) } \\
& \text { que - que - rér - hóm - bre - vi - vír } \uparrow / / \quad 8 \quad \mathrm{~m} \\
& \left(3^{\mathrm{a}}, 4^{\mathrm{a}}, 7^{\mathrm{a}}\right. \text { trocaico) } \\
& \text { 455. cuan - do - Diós - quié - re - que - mué - ra } \uparrow / / 8 \quad \mathrm{k} \\
& \left(3^{\mathrm{a}}, 4^{\mathrm{a}}, 7^{\mathrm{a}}\right. \text { trocaico) } \\
& \text { és - lo - cú - ra } \underset{\left(1^{\mathrm{a}}, 3^{\mathrm{a}} \text { trocaico }\right)}{\downarrow}
\end{aligned}
$$

\section{Copla 39}

“Tú $\downarrow /$ que - por - nues - tra - mal - dád $\uparrow / / \quad 8 \quad \mathrm{t}$

$\left(1^{\mathrm{a}}, 7^{\mathrm{a}}\right.$ dactílico)

to - más - te - fór - ma - ser - vil
$\quad\left(2^{\mathrm{a}}, 4^{\mathrm{a}}, 7^{\mathrm{a}}\right.$ mixto)
$\mathrm{y}$ - bá - xo - nóm - bre $\downarrow / /$

8

Z”

A"'

$\left(2^{\mathrm{a}}, 4^{\mathrm{a}}\right.$ yámbico $)$

460. Tú $\downarrow /$ que a - tu - di - vi - ni - dád $\uparrow / /$

$\left(1^{\mathrm{a}}, 7^{\mathrm{a}}\right.$ dactílico)
jun - tás - te - có - sa - tan - víl $\uparrow / /$
$\left(2^{\mathrm{a}}, 4^{\mathrm{a}}, 7^{\mathrm{a}}\right.$ mixto $)$
co - mo el - hóm - bre $\downarrow / /$
$\left(3^{a}\right)$

Tú $\downarrow /$ que - tan - grán - des - tor - mén - tos $\uparrow / / \quad 8$

$\left(1^{\mathrm{a}}, 4^{\mathrm{a}}, 7^{\mathrm{a}}\right.$ dactílico $)$

$\mathrm{Su}-$ frís - te $-\sin -$ re - sis - tén - cia $\uparrow / / \quad 8$

( $2^{\mathrm{a}}, 7^{\mathrm{a}}$ mixto)

465. en - tu - per - só - na $\downarrow / /$

$\left(4^{\mathrm{a}}\right)$

nó - por - mis - me - res - ci - mién - tos $\uparrow / /$

$\left(1^{\mathrm{a}}, 7^{\mathrm{a}}\right.$ dactílico $)$

mas - por - tu - só - la - cle - mén - cia $\uparrow / /$

$\left(4^{\mathrm{a}}, 7^{\mathrm{a}}\right.$ dactílico)

me - per - dó - na $\downarrow$ ” //

$\left(3^{a}\right)$ 


\section{Copla 40}

\begin{tabular}{|c|c|}
\hline $\begin{array}{c}\text { A - sí } \uparrow / \text { con - tál }- \text { en }- \text { ten }- \text { dér } \uparrow / / \\
\left(2^{\mathrm{a}}, 4^{\mathrm{a}}, 7^{\mathrm{a}} \text { mixto }\right)\end{array}$ & 8 \\
\hline $\begin{array}{c}\text { 470. tó }-\operatorname{dos}-\operatorname{sen}-\text { tí }^{\mathrm{a}}-\operatorname{dos}-\mathrm{hu}-\operatorname{má}-\operatorname{nos} \uparrow / / \\
\left(1^{\mathrm{a}}, 4^{\mathrm{a}}, 7^{\mathrm{a}} \text { dactílico }\right)\end{array}$ & 8 \\
\hline $\operatorname{con}-\operatorname{ser}-\operatorname{vá}-\mathbf{d o s} \downarrow / / /$ & 4 \\
\hline $\begin{array}{c}\text { cer }- \text { cá }- \text { do }-\underset{d e}{d}-\mathrm{su}-\mathrm{mu}-\mathrm{jér} \uparrow / / \\
\left(2^{\mathrm{a}}, 7^{\mathrm{a}} \text { mixto }\right)\end{array}$ & 8 \\
\hline $\begin{array}{c}\mathrm{y}-\mathrm{de}-\mathrm{hí}-\mathrm{jos} \downarrow / \mathrm{y}-\mathrm{her}-\text { má }- \text { nos } \downarrow / / \\
\left(3^{\mathrm{a}}, 7^{\mathrm{a}} \text { trocaico }\right)\end{array}$ & 8 \\
\hline $\mathrm{y}-\operatorname{cri}-\mathbf{a}-\operatorname{dos} \underset{\left(3^{\mathrm{a}}\right)}{\downarrow} / /$ & 4 \\
\hline $\begin{array}{l}\text { 475. dió el }- \text { ál }-\underset{\left(1^{\mathrm{a}}, 2^{\mathrm{a}}, 7^{\mathrm{a}} \text { mixto }\right)}{ }=\text { la }- \text { dió } \downarrow / / \\
\end{array}$ & 8 \\
\hline $\begin{array}{c}\mathrm{el}-\mathrm{cual}-\mathrm{la}-\text { pón }- \text { ga en }-\mathrm{el}-\mathrm{cié}-\mathbf{l o} \uparrow / / \\
\left(4^{\mathrm{a}}, 7^{\mathrm{a}} \text { dactílico }\right)\end{array}$ & 8 \\
\hline en $-\mathrm{su}-\mathrm{gló}-\underset{\left(3^{\mathrm{a}}\right)}{\mathbf{r i a} \downarrow / /}$ & 4 \\
\hline $\begin{array}{c}\text { y aun }- \text { que }- \text { la }- \text { ví }- \text { da }-m u-\text { rió } \uparrow / / \\
\left(4^{\mathrm{a}}, 7^{\mathrm{a}} \text { dactílico }\right)\end{array}$ & 8 \\
\hline $\begin{aligned} \text { nos }- \text { de }- \text { xó }- \text { hár }- \text { to }- \text { con }- \text { sué }- \text { lo } \uparrow / / \\
\\
\left(3^{\mathrm{a}}, 4^{\mathrm{a}}, 7^{\mathrm{a}} \text { trocaico }\right)\end{aligned}$ & 8 \\
\hline 480. su - me - mó - ria $\downarrow / / /$ & 4 \\
\hline
\end{tabular}

A composición poética consta de cuarenta coplas de pie quebrado. Según A. Quilis (2001, 111): "La sextilla más conocida es la llamada Copla de pie quebrado, copla de Jorge Manrique o Estrofa manriqueña" que difiere de la sextilla tradicional en que "los versos tercero y sexto son tetrasílabos, en lugar de octosílabos, como el resto de la estrofa". Cada copla, a su vez, está formada por dos sextillas de pie quebrado. Para el estudio de éstas hemos utilizado la edición de Antonio Serrano de Haro. En los sucesivos puntos del artículo tendremos en cuenta esta edición y no otros corpus donde algunos versos difieren de la versión del autor mencionado. Por ello, algunos cómputos serán distintos de otras ediciones de otros estudiosos. 


\subsection{Análisis silábico}

En total hay 313 versos octosílabos, es decir, el $65.2 \%$ del total. De éstos, 173 (el 55.2\%) poseen 8 sílabas fonológicas equivalentes a 8 métricas; 37 (el 7.7\%) tienen 8 sílabas fonológicas que al acabar la última con un acento final oxítono se hubieran convertido en nueve métricas de no ser por la sinalefa; 6 versos con nueve sílabas fonológicas acabados en sílaba oxítona se computan como 8 métricas por las dos sinalefas presentes ${ }^{2} ; 45$ versos (el 9.3\%) tienen 7 sílabas fonológicas que se convierten en 8 métricas por acabar en acento oxítono; se registran 49 (el $10.2 \%$ ) con 9 sílabas fonológicas que se convierten en versos de 8 sílabas métricas por una sinalefa, el verso 349 hacemos un hiato entre su y honra; contabilizamos 6 versos de 10 sílabas fonológicas con dos sinalefas dando lugar a 8 métricas.

Tenemos 3 versos heptasílabos. El 293 posee 7 sílabas fonológicas igual a 7 métricas. El verso 67 tiene 7 fonológicas que acaban siendo siete métricas por la presencia de una sinalefa y el final oxítono del verso y el verso 473 donde contamos una sinalefa entre $y$ hermanos.

De los 480 versos, hay 122 en los que se produce la sinalefa, un $25,4 \%$. Ésta se cumple regularmente entre vocales inacentuadas en 111 versos, un $23 \%^{3}$; tan sólo 11 poseen sinalefa entre vocal átona más tónica ${ }^{4}$ y 6 a la inversa, entre tónica y átona ${ }^{5}$. Registramos 3 versos con sinalefa entre dos vocales tónicas ${ }^{6}$. Para mantener el metro octosílabo en los versos 419, entre la y otra no hemos realizado sinalefa y el 152 en el que no enlazamos las voces toda hora.

La aspiración de la $h$, procedente principalmente de la f- inicial latina, impide la unión de las vocales en los versos 182, 193, 196, 199, 202, 244, 272, 283, 298, 355, 473, 4797. Los versos

$\overline{{ }^{2} \text { En }}$ el verso 329 hay sinalefa y sinéresis.

${ }^{3}$ Hemos registrado dieciséis versos donde a pesar de haber una pausa se hace la sinalefa entre las vocales átonas. Versos: 10, 76, 229, 230, 233, 263, 313, 320, 322, $323,325,326,328,329,334,335$.

${ }^{4}$ Versos: 20, 23, 113, 219, 240, 349, 351, 415, 418, 421, 443 (dos en el mismo verso: "que esta otra vida tercera").

${ }^{5}$ Versos: 70, 264, 285, 301, 304, 475.

${ }^{6}$ Versos: 144, 163, 416.

${ }^{7}$ Según Ramón Menéndez Pidal en el Manual de gramática histórica. Madrid: Espasa Calpe, 1958, p.121: "La F se conservó en la lengua escrita hasta fines del siglo XV 
391 y 399 tienen la $h$ aspirada de las voces hazaña y halago que son de procedencia árabe: hásana y hálaq, según El Diccionario Crítico y Etimológico de Corominas y J.A Pascual.

Se produce la diéresis principalmente en los diptongos [jó] glorïosa(v.149, 413), [wí] juïzio(v.238), [já] Octavïano (313), Aurelïano (322), Adrïano (328). Encontramos sinéresis en el verso 329: "Teodosio, en humanidad". Según Juan Cano (1931, 231-233):"En los octonarios aparece la sinalefa mucho más que el hiato [...] es indiscutible que en los romances viejos la sinalefa es lo corriente, y el hiato es la excepción [...] después de todo la sinalefa es lo natural en el lenguaje, al contrario del hiato que es lo artificial".

1.1.1. El pie quebrado. Los versos de pie quebrado, en su mayoría, son tetrasílabos 8 : 93 versos (el 26.6\% del total) tienen cuatro sílabas fonológicas equivalentes a cuatro métricas 917 versos (el 3.5\%) tienen 5 sílabas fonológicas que se convierten en cuatro métricas por una sinalefa ${ }^{10}$. 18 poseen 3 sílabas fonológicas que equivalen a cuatro métricas por ser oxítona la sílaba final del verso ${ }^{11}$. Por otra parte, hay 27 versos pentasílabos, el 5.6\% del total: 17 de ellos con 5 sílabas fonológicas equivalentes a 5 métricas ${ }^{12}$; 9 con 4 sílabas fonológicas que son 5 métricas por finalizar con acentuación oxítona ${ }^{13}$. El verso 27 posee 5 sílabas fonológicas pero al ser oxítono serían 6 métricas que se convierten en 5 por la sinalefa. Tenemos las siguientes excepciones en donde no se cumple el patrón métrico del verso de pie quebrado manriqueño: los versos 363 y 366 tienen 5 sílabas

\footnotetext{
[...] pero luego fue sustituida por la $\mathrm{h}$, que era verdadera aspirada en los siglos XV y XVI".

${ }^{8}$ En concreto, hemos contabilizado 127 de los 480 versos de la composición; supone el $26.4 \%$.

${ }^{9}$ El verso 144: No hay lugar tiene 4 sílabas fonológicas. Al haber una sinalefa y ser el verso oxítono, pasa a tener 4 sílabas métricas.

${ }^{10}$ Versos: 15, 21, 39, 66, 81, 180, 198, 219, 240, 261, 264, 273, 285, 351, 372, 453, 462.

${ }^{11}$ Versos: 9, 12, 45, 48, 51, 54, 69, 72, 141, 147, 231, 249, 252, 309, 312, 375, 411, 441,444 . Consideramos agudas las palabras que acaban en diptongación tónica.

${ }^{12}$ Versos: 24, 63, 102, 120, 138, 183, 186, 294, 321, 324, 330, 399, 402, 417, 420, $459,465$.

${ }^{13}$ Versos: 30, 93, 96, 150, 213, 216, 234, 315, 318.
} 
fonológicas pero se convierten en 6 métricas por ser oxítonos: "en la joventud", "en la senectud" y el verso 408: "que os llama" con 4 sílabas fonológicas pasa a 3 métricas por la presencia de una sinalefa.

Según Navarro Tomás $(1961,175)$ "Jorge Manrique observó en este punto la regla practicada en su tiempo de no aplicar el quebrado pentasílabo sino en condiciones de compensación o sinalefa respecto al octosílabo precedente".

Siguiendo al mencionado investigador $(1961,175)$, "después de los octosílabos segundo y cuarto, agudos, siguen pentasílabos de compensación". Para Isabel Paraíso (2000, 106-107): "la compensación consiste en que un verso agudo -nuevamente el primero- embebe la sílaba inicial del siguiente, hipermétrico". En nuestro estudio, hemos recogido los siguientes: Copla $3^{\text {a: }}$ : que van a dar a la mar/ que es el morir; Derechos a se acabar/y consumir; porque todo ha de passar/ por tal manera. Copla $\mathbf{6}^{\mathbf{a}}$ : si bien usáremos del/ como dememos. Copla $\mathbf{8}^{\mathbf{a}}$ : y la fuerçacorporal/ de juventud; Cuando llega al arrabal/de senectud. Copla 16: ¿Los infantes de Aragón/qué se hizieron?; ¿Qué fue de tanta invención/ como truxieron?. Copla $1 \mathbf{1 8}^{\mathbf{a}}$ : cuán contrario, cuán cruel/ se le mostró; ;Cuán poco duró con él/ lo que le dio!. Copla 27': Julio César, en vencer/ y batallar; Aníbal, en el saber/ y trabajar; Tito, en liberalidad/con alegria; Marco Atilio, en la verdad/ que prometía. Copla 31': que con su braço Pintól en la juventud; Agora las renovó/ en la senectud. Copla 35': tampoco no es eternal/ ni verdadera; Que la otra temporal/ perescedera.

Para Navarro Tomás $(1961,175)$, la "indicada regla era meramente potestativa. El autor no la infringió ni la aplicó de manera sistemática" porque, en algunas coplas, se registran octosílabos agudos seguidos de tetrasílabos sin compensación". Así ocurre en las: Copla 2: : Pensando que ha de durar/lo que espera. Copla 4': Aquél sólo invoco yo/ de verdad; El mundo no conosció/ su deidad. Copla 6 ${ }^{\mathbf{a}}$ : espara ganar aquél/ que atendemos. Copla 8a: la gentil frescura y tez/ de la cara; Cuando viene la vejezl ¿cuál se para? Copla 28 ${ }^{\mathbf{a}}$ : Marco Aurelio, en igualdad/ del semblante; En disciplina y rigor/ de la guerra; Camilo, en el gran amor/ de su tierra. Copla 32': Si de las obras que obról fue servido; $Y$ en Castilla quien siguió/ su partido. Copla $\mathbf{3 3}^{\text {a: }}$. 
a que no puede bastar/ cuenta cierta; Vino la muerte a llamar/ a su puerta. Copla 39': Juntaste cosa tan vil/ como el hombre.

Por último tenemos versos de pie quebrado en los que se produce una sinafia ${ }^{14}$. Esto sucede en los versos siguientes: Copla 9a: Se sume su gran alteza/ en esta vida. Copla 10': Ni estar estable ni queda/ en una cosa. Copla 12: y la muerte, la celada/ en que caemos. Copla 13a: el ánima gloriosa/ angelical. Copla 250: Manrique tan famoso/ y tan valiente. Copla 34 ${ }^{\mathrm{a}}$ : dexad el mundo engañoso/ y su halago; muestre su esfuérço famoso/ en este trago. Copla 35a : de fama tan glorïosa/ acá dexáis. Copla 39': sufriste resistencial en tu persona. Según Navarro Tomás (1965, 175): "Tanto la compensación como la sinalefa, con el alargamiento que el pentasílabo representa, prestan cierto relieve al pie quebrado. La compensación procede con orden simétrico, guardando el equilibrio de la estrofa; la sinalefa, como con frecuencia el octosílabo dactílico, apoya la segunda mitad.”.

Para dicho investigador $(1961,175)$ : "Cuando la primera sílaba del pentasílabo lleva acento, auque teóricamente empalme con el octosílabo anterior, sin duda mantiene su carácter dactílico: “que es el morir”, “¿Qué fizieron?’[...] se ha probado experimentalmente que el enlace entre el octosílabo y el pie quebrado se acomoda al tiempo regular del período rítmico".

Por último entre un octosílabo acabado en vocal y un tetrasílabo que se inicia también por ésta no registramos sinalefa: Copla $2^{\mathbf{a}}$ : cómo en un punto s'es ido/y acabado. Copla 13a: toviéramos a toda hora/ y tan presta. Copla 20': metióle la muerte luego/ en su fragua; cuando más ardía el fuego/ echaste agua. Copla 22: que tan alto fue subida/ y ensalzada. Copla 38: cuando Dios quiere que muera/ es locura. Copla 40': el cual ponga en el cielo/ en su gloria.

\subsection{Análisis acentual}

En lo que se refiere a la acentuación, el acento versal recae en la $7^{\mathrm{a}}$ sílaba de los octosílabos, y en la $3^{\mathrm{a}}$ de los tetrasílabos.

\footnotetext{
${ }^{14}$ Definida por Domínguez Caparrós, José, en su Diccionario de métrica española. Madrid: Alianza Editorial, 1999, como "sinalefa entre la sílaba final de un verso que termina en palabra llana y la sílaba inicial del verso siguiente-que sobra en el cómputo silábico de este verso".
} 
Estos últimos tienen, generalmente, sólo un acento. Sin embargo, encontramos que los versos: 9, 12, 90, 111, 219, 264, 285, $300,309,312,351,369,381,393,453,456$ tienen los acentos en la $1^{\mathrm{a}}$ y $3^{\mathrm{a}}$ sílabas; los versos $33,240,447$ lo poseen en la $2^{\mathrm{a}}$ (acento antirrítmico y extrarrítmico) y $3^{\mathrm{a}} \mathrm{e}$, incluso, el verso 177 tiene tres acentos en la $1^{\mathrm{a}}, 2^{\mathrm{a}}, 3^{\mathrm{a}}$ sílabas. En los pentasílabos, el acento recae en la $4^{\mathrm{a}}$ sílaba; a veces, éstos tienen también más de uno. Así, registramos la acentuación en las sílabas $2^{\mathrm{a}}$ y $4^{\mathrm{a}}$ de los versos: $24,102,120,330,402,459$, e inclusive, en las $1^{\mathrm{a}}$ y $4^{\mathrm{a}}$ del 27 y el 183 .

La mayoría de los versos son paroxítonos, el 75, 8\%. Sin embargo, encontramos 110 versos oxítonos con un porcentaje del $24,1 \%$.

En las coplas, la sílaba sobre la que recae el acento es de signo impar. El ritmo en éstas es trocaico ${ }^{15}$. Como dice Navarro Tomás $(1961,171)$ su uso:"había obedecido probablemente a influencia galaico-provenzal. El testimonio de las Coplas revela la señalada inclinación que en el tiempo de Jorge Manrique operaba para restablecer en el campo de la poesía culta el modo octosilábico polirrítmico usado en todo tiempo por la lírica popular castellana".

Detrás de la aparente sencillez de la composición, encontramos que el poeta realiza una organización acentual bastante compleja. Al analizarla, observamos que esta riqueza de acentos proporciona una viveza al contenido que no deja indiferente al lector. Hemos registrado, en total, 28 esquemas acentuales en los versos octosílabos. La acentuación trocaica representa el $29.5 \%$ del total. Con acento dactílico el porcentaje es del $12.2 \%$ y las variedades mixtas el $23.3 \%$.

\subsection{Análisis de las pausas}

Las dos sextillas de cada copla suelen formar cuadros narrativos bien definidos con pausas estróficas en su final. Exceptuamos las coplas diecinueve, veinticuatro, veintiséis, veintisiete, veintiocho y treinta y nueve. Todas éstas forman una unidad

\footnotetext{
${ }^{15}$ Salvo en los versos de pie quebrado: $24,27,30,63,93,96,102,120,138,150,183$, $186,213,216,234,294,315,318,321,324,330,339,402,414,417,420,459$, 465 por ser pentasílabos y los versos heptasílabos: $67,293$.
} 
temática, entrelazándose las sextillas por las enumeraciones que realiza en ellas nuestro poeta. Otra ausencia de pausa estrófica aparece en la copla treinta y tres. En ésta, tenemos tres oraciones temporales antepuestas a la oración principal que se concentra en los tres últimos versos de la copla. Según Salinas $(1974,181)$ "La copla 33 es funcionalmente dentro del poema, un elememto de enlace: su papel es hacernos pasar de la vida del Maestre -resumida en los nueve primeros versos- a la llegada de la muerte en los tres últimos".

Son numerosos los encabalgamientos de la composición. En nuestro estudio, ante este fenómeno, hemos considerado ausencia de pausa porque, según A. Quilis $(2001,197)$ : “el efecto del encabalgamiento es el mismo se mire por donde se mire; si no se realiza la pausa, se viola el principio de pausación final de cada verso; si se realiza, se separan los términos que sintagmáticamente siempre están unidos".

Hay que destacar que los encabalgamientos analizados son suaves. De esta forma, Manrique marca los momentos de carácter reflexivo que quiere conseguir en el relato de determinados fragmentos. Son todos sirremáticos:

1.3.1. Sirrema formado por sustantivo+adjetivo: señoríos / derechos ( copla 3, vv 28-29); nobleza / tan crescida (copla 9, vv 98-99); su rueda / presurosa (copla 10, vv 116-117); la señora / descompuesta (copla 13, vv 155-156); escrituras / ya passadas (copla 14, vv 158-159); venturas / transtornadas (copla 14, vv161-162); atavíos / tan sobrados (copla 19, vv 224-225); ancianía / bien gastada (copla 31, vv 368-369); rey / verdadero (copla 33, vv 389-390); estados / mundanales (copla 36, vv 422423); pecados / infernales (copla 36,vv 425-426).

1.3.2. Sirrema formado por sustantivo + complemento determinativo: morada / sin pesar (copla 5, vv 50-51); tez /de la cara (copla 8, vv 86-87); corporal / de juventud (copla 8, vv 92-93); arrabal / de senectud (copla 8, vv 95-96); pastores / de ganados (copla 14, vv167-168); llamas / de los fuegos (copla 17, vv 196197); fuegos encendidos / de amadores (copla 17, vv 197-198); reales / del tesoro (copla 19, vv 221-222); caballos / de su gente 
(copla 19, vv 223-224); rocio / de los prados (copla 19, vv 227228); virtuoso / de la gente (copla 25, vv 290-291); liberalidad / con alegría (copla 27, vv 320-321); igualdad / del semblante (copla 28, vv 326-327); rigor / de la guerra (copla 28, vv 332333); amor / de su tierra (copla 28, vv 335-336); caballería / de la Espada (copla 31, vv 371-372).

1.3.3. Sirrema formado por una perífrasis verbal: descendió / a nascer (copla 6, vv 69-70).

1.3.4. Encabalgamiento oracional: ríos / que van (copla 3, vv 25-26); aquél / que atendemos (copla 6, vv 65-66); suelo / do murió (copla 6, vv 71-72); riqueza / que nos dexan (copla 10, vv 109-110); Fortuna / que revuelve (copla 10, vv 115-116); La celada / en que caemos (copla 12, vv 137-138); Los troyanos / que sus males (copla 15, vv 169-170); Señor / que le siguió (copla 20, vv 233-234); Claridad / que estando (copla 22, vv 263-264); Hazañas / que hizieron (copla 23, vv 271-272); La verdad / que prometía (copla 27, vv 323-324); Vasallos / que le dieron (copla 29, vv 347-348); Guerra / que hazía (copla 30, vv 356-357); Estorias / que con su braço (copla 31, vv 361-362); Hazaña / a que no puede (copla 33, vv 391-392); Afruenta / que os llama (copla 34, vv 407-408); Galardón / que en este (copla 37, vv 436-437).

Es peculiar el encabalgamiento de los versos 292-293 de la copla veinticinco entre el nombre propio y el apellido: Rodrigo / Manrique.

Registramos tan sólo tres versos polipausados el 230, 269 y el 274. En la composición hay una serie de versos donde encontramos braquistiquios que aparecen en los versos: 19, 32, 50, 59, $64,76,82,128,160,206,230,233^{16}, 235,269,283,293,313$, $314,316,317,319,320,322,323,325,328,329,334,433,460$, 463, 473. Como señala A. Quilis $(2001,90)$ : “es un corte, una pausa breve, que como tal, ya supone el interés del poeta por poner alguna cosa de relieve [...] es una forma de potenciación

\footnotetext{
${ }^{16} \mathrm{El}$ verbo tuvo se halla entre pausa versal y una interna. Lo mismo sucede en los versos 319, 320, 322 y 323. En el primero, el elemento que se quiere destacar es la cualidad de bondad; en el segundo la figura de Tito; en los dos últimos en su braço y Marco Atilio.
} 
estilística de ciertas palabras...”. En las coplas veintisiete y veintiocho, los braquistiquios ayudan a ensalzar la figura paterna. El poeta confiere al Maestre las virtudes de relevantes personajes históricos: Julio César, Africano, Aníbal, Tito, Aureliano, etc.

Registamos las siguientes pausas internas en los versos 10, 50, 106, 137, 188, 194, 208, 211, 212, 224, 227, 229, 230, 235, 263, 289, 293, 397, 457, 469.

\subsection{Análisis tonal}

A grandes rasgos, expondremos, en este epígrafe, los diversos patrones entonativos analizados en las coplas manriqueñas. La entonación descendente la tenemos en los enunciados declarativos: verso 1: Recuerde el alma dormida; verso 43: A aquél sólo me encomiendo; verso 45: Aquél sólo invoco yo; verso 55: Partimos cuando nascemos; verso 56: andamos mientras vivimos; verso 79: dellas deshaze la edad; verso 118: la cual no puede ser una; verso 178: vengamos a lo de ayer; verso 475: dio el alma a quien gela dio; el verso 19 forma una oración enunciativa declarativa negativa, acompañada de un no exclamativo con entonación descendente. Encontramos, lógicamente, en el verso final de las dos sextillas de cada copla juntura terminal descendente. Cada una de ellas forman, como hemos dicho anteriormente, un cuadro narrativo de ideas muy concentradas; Según Navarro Tomás $(1961,170)$ :

La diferencia de rimas entre las dos sextillas de cada pareja dio lugar a que cada una de ellas llegara a considerarse como unidad independiente. Ocurre además que la mayor parte de las sextillas de las Coplas ofrecen individualidad bien definida, no sólo por razón de sus rimas, sino por su propio sentido. En varios casos, sin embargo, entre una sextilla impar y la que le sigue existe un enlace sintáctico y semántico que da a entender que su originaria agrupación en parejas no significaba una práctica meramente formal. Confirma esta relación el hecho de que en ningún caso una sextilla par aparezca trabada con la impar siguiente. Sólo con ocasión de las sextillas 65-66 se advierte que el sentido desborda la pareja y se extiende sobre la inmediata.

Conceptualmente, hay una copla que desborda su molde métrico y continúa en la siguiente; esto sucede con la veintisiete, 
según nuestra enumeración, que continúa en la veintiocho, en ellas el poeta realiza el panegírico de Don Rodrigo Manrique, atribuyéndole las cualidades de determinados personajes de relevancia histórica. En este caso, la sextilla par enlaza con una impar desbordando el molde estrófico que hay entre las coplas, pues existe un continuum de enumeraciones incompletas con las mismas estructuras entonativas y sintácticas.

Por otra parte, Observamos en nuestro estudio que las dos estrofas de la copla veinticuatro se enlazan con el empleo de nueve junturas terminales descendentes desde el verso 277 hasta el 284, sobrepasando el límite de la primera sextilla, porque forman una enumeración incompleta de símbolos que reflejan el poder terrenal, cuya conclusión finaliza con una interrogativa pronominal de entonación descendente en el verso 285: ¿Qué aprovecha? Lo mismo sucede en la copla veintiséis, donde tenemos una sucesión de exclamativas con entonación final descendente, ensalzando la figura paterna. En la treinta y tres, los tres tercetos forman una enumeración incompleta de tres oraciones temporales hiperbatizadas cuyo tetrasílabo tiene, por esta razón, entonación descendente, y todo ello agrupa un bloque significativo, que hace desaparecer la diferenciación temática entre las sextillas. La copla treinta y nueve también forma una unidad. Así, encontramos tres tercetos, entrelazados y encabezados por el vocativo $T u ́$, que forman una enumeración incompleta con una estructura entonativa y sintáctica similar. El pronombre Tú exclamativo con juntura descendente, se refiere al Dios hecho hombre, seguido éste por tres oraciones de relativo con juntura terminal descendente en los tres tetrasílabos de las sextillas, de esta manera, nuestro poeta dibuja en ellos los padecimientos del Hijo de Dios. La copla 40 forma una unidad, que traspasa la primera sextilla en la que narra la muerte de su padre como si el lector observara la escena de un cuadro potenciada por las junturas terminales descendentes de cada terceto.

Tienen curva de entonación descendente los versos que forman el segundo elemento de una coordinada copulativa: 15,30 , $33,39,75,91,171,187,189,221-222,223-224$ (juntura terminal descendente situada ante la pausa en mitad del verso), 261, 273, 315, 318 (coincide, además, con final de sextilla), 339, 453. 
Son muy numerosas en esta composición las enumeraciones incompletas que llevan todas ellas juntura terminal descendente en los versos: 26, 27, 31, 85, 87, 97, 103, 159, 160, 188 (en mitad del verso, se sitúa la juntura entonativa descendente), 193, 194, 199, 202, 208, 211, 212, 217, 219, 220, 247, 248, 249, 265, 266, 267 (aunque tenga una conjunción $y$ es un enumeración incompleta), 367, 376 (enumeración incompleta a pesar de la $y$ conjunción), 385-39417, 439, 452, 453, 471, 473, 474.

Normalmente, los versos tetrasílabos de los tercetos, que no coinciden con final de sextilla, tienen entonación descendente, porque desarrollan una idea con un sentido completo en dicha estrofa que forma de oración. Esto sucede en los versos: 9, 15, $18,27,45,51,63,81,105^{18}, 117,123,129,141,171,177,231$, 237, 246, 297, 315,321, 327, 339, 345, 375, 381, 399, 411, 417, 423, 429, 447, 453, 477.

En los versos 85, 397, hemos puesto juntura descendente también en mitad del verso pues tras un verbo decir con matiz invocativo presenta un descenso entonativo; lo mismo ocurre con el verbo ver del verso 211; en el verso 269, la entonación desciende porque hay dos exhortaciones con el verbo decir $\mathrm{y}$ con la invocación a la muerte: Di, muerte, ¿dó los escondes...

Las oraciones interrogativas pronominales tienen juntura terminal descendente en los versos ${ }^{19}: 90,111,136^{20}, 177,181,183$, $184,186,192,195,198,201,204,226,228,250,252,264,270$, 285,351 .

Las oraciones exclamativas también tienen entonación descendente al final del enunciado exclamativo, algunas coinciden a veces con el final del terceto; los versos son: el 102, 207, 208-210, 211-213, 216, hemos colocado juntura descendente en los versos 233 y 234 porque la conjunción y enlaza dos versos

\footnotetext{
${ }^{17}$ Encontramos una sucesión de oraciones subordinadas temporales, que se circunscriben a los tres tercetos, formando un enumeración incompleta a pesar de ir antepuestas a la oración principal.

${ }^{18}$ Este verso, final de un terceto, podría incluirse en el epígrafe de enumeraciones incompletas, pues el contexto de la sextilla podría ser un cómputo de personas que obtienen su riqueza con malas artes.

${ }^{19}$ En algunos de estos versos, la entonación descendente final de las interrogativas pronominales coincide con la juntura terminal descendente del final de la sextilla.

${ }^{20}$ El verso no tiene el interrogante al final y, aunque le siga una conjunción copulativa, forma en sí mismo, una pregunta con pronombre interrogativo.
} 
exclamativos, 238, 301, 303, 304, 306, 307, 308, 309, 310-312 ${ }^{21}$. Por último la entonación desciende en los vocativos de los versos 433, 457, 460, 463, éstos tres últimos están encabezados con el pronombre tú que es una exhortación de la figura de Dios.

\subsubsection{Tenemos entonación ascendente:}

1.4.2.1. Cuando los versos son los sujetos de la oración que se desarrollará posteriormente: $11,67,91-93^{22}, 127,130-131^{23}$, 133-135 253- 255, 361-363, 379, 400, 415, 421, 427, 430, 454.

1.4.2.2. Cuando el sentido del verso es incompleto al faltarle algún tipo de complemento sintagmático, que aparecerá desarrollado en los versos siguientes, así ocurre en: 2, 3, 5, 17, 20, 21, $23,47,49,52,53,57,101,119,122,140,146,147,148,149$, $173,175,236,245,251,287,299,331,346,362,363,365,383$, $385,386,388,392,395,401,404,409,431,434,437,445,446$, $448,449,451,464,470,476$. Dentro de este apartado también, incluimos los versos que completan su sentido con una oración subordinada situada en el verso siguiente 24 : $13,40,61,94,104$, $110^{25}, 112,124,125,134,157,164-166,171,172,176^{26}, 179$, 185, 200, 203, 298-300, 406-408, 424- 426. También, el primer término de las oraciones comparativas tiene su flexión final entonativa ascendente: $179-180,254-255,358-360,418-420$, $461-462$.

1.4.2.3. Cuando tenemos el primer elemento de una oración coordinada copulativa: $14,29,35,38,70,74,121,170,221,223$, 260, 272, 275, 293, 302, 305, 314, 317, 329, 338, 341, 347, 382, $398,416,428,458,472^{27}$.

${ }^{21}$ Sucede lo mismo que con los versos 233 y 234.

${ }^{22}$ Todo el terceto es sujeto, además en el verso siguiente hay un todo pronominal que sustituye toda la enumeración anterior, reforzando la función de sujeto.

${ }^{23}$ Incluimos este verso pues es una oración adjetiva explicativa en aposición al sintagma nominal sujeto.

${ }^{24}$ Los encabalgamientos sirremáticos con oraciones de relativo no los incluimos en este apartado.

${ }^{25}$ Este verso se complementa con una interrogativa pronominal.

${ }^{26}$ Este verso se completa con el siguiente que es una oración interrogativa indirecta.

${ }^{27}$ En los versos 473 y 474, aparece la conjunción copulativa y; sin embargo, hemos 
1.4.2.3. El hipérbaton:

1.4.2.3.1. Cuando una oración subordinada se antepone a la principal: 16, 46, 76-77, 13928, 142-143, 145, 163, 214, 235, 256, $274,286,352,355,391-393,403-405^{29}, 433-435,455,478$.

1.4.2.3.2. Por anteposición de los elementos sintagmáticos dentro de una oración: $41,68,73,76,82-83,97-99,100,107$, $151,209,215,230,232,241,256,295,311,343,344,349,350$, 353, 364, 373-374, 376-377, 403, 412- 413, 440-441, 443, 457, 460, 463, 466- 467, 479.

1.4.2.3.3. Cuando hay un inciso explicativo: $8,10,32,50-51$, $59,64,82,106,128,131,153,205-206,229-230,235,242-243$, $263,274,289-294,374,380$ aunque sea una oración condicional, 469.

1.4.2.3.4. Hay juntura terminal ascendente tras el antecedente de una oración adjetiva especificativa: $34,104,133-134,157$, 200, 203.

1.4.2.3.5. Hemos observado que los versos 138 (en la segunda parte de la coordinación de la estructura interrogativa), 190 y 252 son oraciones interrogativas absolutas por lo que su juntura entonativa es ascendente.

Por último, en las coplas 27 y 28 encontramos juntura entonativa ascendente, en mitad de sus versos tras los nombres de los personajes históricos; ésta tiene una función demarcativa no distintitiva marcada por la ausencia del verbo ser.

\subsection{Análisis de la rima}

Como dice Navarro Tomás $(1961,176)$ el "principal elemento de variedad en la estrofa es la rima". Ésta es total y está es encadenada. Repite siempre el mismo orden de rima: copla $1^{\mathbf{a}}$ : $a b c$

\footnotetext{
puesto juntura terminal descendente, porque los elementos coordinados forman una enumeración incompleta.

${ }^{28}$ Consideramos este verso como una oración de gerundio causal.

${ }^{29}$ Los tres versos funcionan como una oración consecutiva.
} 
$a b c$, def def; copla $\mathbf{2}^{\text {a': }}$ ghe ghe, ijk ijk, etc.

Esta variación se corrobora con la clasificación y el recuento realizado de éstas ${ }^{30}$. Así tenemos:

1.5.1. Rimas oxítonas: registramos 16 rimas oxítonas en 118 palabras. Lo que supone un promedio del $24.5 \%$. Según Navarro Tomás $(1966,176)$ "sobresalen en las rimas agudas [...] las vocales más abiertas y claras".

1.5.2. Rimas paroxítonas: Como reseña el investigador antes mencionado $(1961,176)$, la rima es "predominantemente llana". E1 $75.4 \%$ de los versos la tiene. Hemos contabilizado 103 rimas paroxítonas en 360 palabras.

Comprobamos que la creatividad del poeta, observada en todos los niveles analizados, se refleja no sólo en la variedad de las rimas sino también en la riqueza léxica de éstas.

Por otro lado, hemos hecho un recuento de las rimas gramaticales que asciende al $34,5 \%$ frente al $14,7 \%$ que son antigramaticales.

Como conclusión de nuestro análisis, hemos de decir que Jorge Manrique crea una composición en la que hay una magistral y compleja utilización de los recursos métrico-estilísticos acompañados de una gran riqueza léxica, que se refleja también en la variedad de la rima, mostrada en nuestro estudio. La genialidad de nuestro autor consiste en que la sencillez es mera apariencia, pues tras ella, normalmente, se esconde la creatividad de nuestro poeta, manifestándose en todos los niveles analizados en nuestro trabajo.

Según Navarro Tomás $(1973,84)$ :

Bajo su sencilla apariencia, las Coplas encierran una compleja y refinada estructura métrica. No escogió Jorge Manrique para su elegía la solemne octava de arte mayor ni la pulida copla real. En sus manos, la ligera sextilla de pie quebrado, sin perder su acento lírico, adquirió madurez y gravedad. El octosílabo aparece en esta poesía como un dúctil instrumento utilizado en toda la variedad de sus recursos, no alcanzada en

$\overline{{ }^{30} \mathrm{En}}$ el texto hemos puesto en negrita las terminaciones de las palabras finales de los versos para que se observe esta variedad léxica y rítmica de la composición. 
con plenitud obras anteriores [...] A su trabado conjunto deben sin duda las Coplas su particular equilibrio y armonía.

\section{Bibliografía}

Corominas, J., Pascual, J.A.: Diccionario Crítico Etimológico Castellano e Hispánico. Madrid: Gredos, 1991.

CANO, J.: "La importancia relativa del acento y de la sílaba en la versificación española". Romanic Review, 1931, 22, pp. 223-233.

Domínguez CAPARrós, J.: Diccionario de métrica española. Madrid: Alianza Editorial, 1999.

MenÉndez Pidal, R.: Manual de gramática histórica española. Madrid: Espasa Calpe, 1958.

Navarro Tomás, T.: "Métrica de las Coplas de Jorge Manrique". Nueva Revista de Filología Hispánica, 1961, XV, pp. 169-179.

-: Los poetas en sus versos desde Jorge Manrique hasta García Lorca. Barcelona: Ariel,1973.

Paraíso, I.: La métrica española en su contexto románico. Madrid: Arco/ Libros, 2000.

Quilis, A.: Métrica española. Barcelona: Ariel, 14ª edición, 2001.

SAlinas, P.: Jorge Manrique o tradición y originalidad. Barcelona: Seix Barral, 1974.

Serrano de Haro, A.: Jorge Manrique, obras. Madrid: Alhambra, 1986. 